\title{
The burden of household out-of- pocket healthcare expenditures in Ethiopia: a systematic review and meta-analysis
}

\author{
Moges Tadesse Borde ${ }^{1,2^{*}}$, , Robel Hussen Kabthymer ${ }^{3}$, Mohammed Feyisso Shaka ${ }^{4}$ and \\ Semagn Mekonnen Abate ${ }^{5}$
}

\begin{abstract}
Background: In Ethiopia, household Out-Of-Pocket healthcare expenditure accounts for one-third of total healthcare expenditure, is one of the highest in the world, and still creates barriers and difficulties for households to healthcare access and may delay or forgo needed healthcare use. Despite the presence of a few highly dispersed and inconsistent studies, no comprehensive study was conducted. Therefore, in this systematic review and meta-analysis, we aimed at estimating the pooled estimates of the burden of household Out-Of-Pocket healthcare expenditures among Ethiopian households and identifying its determinants.

Methods: We systematically searched articles from PubMed / Medline and Google scholar databases and direct Google search engine without restriction on publication period. Cross-sectional and cohort articles and grey literature published in English were included. Data were extracted using Microsoft Excel. Two reviewers screened the titles, reviewed the articles for inclusion, extracted the data, and conducted a quality assessment. The third reviewer commented on the review. Articles with no abstracts or full texts, editorials, and qualitative in design were excluded. To assess quality, Joanna Briggs Critical Appraisal Tools was used. A Forest plot was used to present summary information on each article and pooled common effects. Potential heterogeneity was checked using Cochrane's Q test and I-squared statistic. We checked publication bias using a Funnel plot. Moreover, subgroup and sensitivity analyses were performed. Meta-analysis was used for the pooled estimates using RevMan statistical software Version 5.4.1.

Results: In this review, a total of 27 primary articles were included (with a total sample size of 331,537 participants). Because of the presence of heterogeneity, we employed a random-effects model; therefore, the pooled burden household Out-Of-Pocket / catastrophic healthcare expenditure in Ethiopia was strongly positively associated with household economic status. The odds of facing Out-Of-Pocket / catastrophic healthcare expenditures among the poorest quintile was about three times that of the richest ( $\mathrm{AOR}=3.09,95 \% \mathrm{Cl}: 1.63,5.86) p$-value $<0.001$. In addition, on pooled analysis, the mean direct Out-Of-Pocket healthcare expenditures were $\$ 32$ per month (95\%Cl: $\$ 11$, $\$ 52)(S D=\$ 45)$, and the mean indirect Out-of-Pocket healthcare expenditures were $\$ 15$ per month $(95 \% \mathrm{Cl}: \$ 3, \$ 28)$ $(\mathrm{SD}=\$ 17)$. The mean catastrophic healthcare expenditure at $10 \%$ of threshold was also disproportionately higher: 40\% (95\%Cl: 28, 52\%) (SD =20\%). Moreover, the common coping mechanisms were a sale of household assets, support from family, or loan: $40 \%(95 \% \mathrm{Cl}: 28,52 \%)(\mathrm{SD}=20 \%)$.
\end{abstract}

\footnotetext{
*Correspondence: moges125@yahoo.com

${ }^{2}$ Hawassa, Ethiopia

Full list of author information is available at the end of the article
}

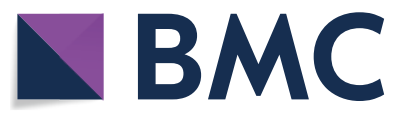

(c) The Author(s) 2022. Open Access This article is licensed under a Creative Commons Attribution 4.0 International License, which permits use, sharing, adaptation, distribution and reproduction in any medium or format, as long as you give appropriate credit to the original author(s) and the source, provide a link to the Creative Commons licence, and indicate if changes were made. The images or other third party material in this article are included in the article's Creative Commons licence, unless indicated otherwise in a credit line to the material. If material is not included in the article's Creative Commons licence and your intended use is not permitted by statutory regulation or exceeds the permitted use, you will need to obtain permission directly from the copyright holder. To view a copy of this licence, visit http://creativecommons.org/licenses/by/4.0/. The Creative Commons Public Domain Dedication waiver (http://creativeco mmons.org/publicdomain/zero/1.0/) applies to the data made available in this article, unless otherwise stated in a credit line to the data. 
Conclusion: Our study revealed the evidence of inequity in financial hardship that the burden of household OutOf-Pocket / catastrophic healthcare expenditures gap persists among Ethiopian households that is unfair and unjust. To reduce the detected disparities in seeking healthcare among Ethiopian households, national healthcare priorities should target poor households. This calls for the Ministry of Health to improve the challenges and their impact on equity and design better prepayment policies and strengthen financial protection strategies to protect more vulnerable Ethiopian households.

Protocol registration: The details of this protocol have been registered on the PROSPERO database with reference number ID: CRD42021255977.

Keywords: Household, Out-of-pocket, Healthcare, Expenditures, Ethiopia, Meta-analysis

\section{Background}

Every citizen has a natural right to get necessary healthcare in all the stages of life, and must not be hampered by household socioeconomic status [1]. In recent years, policymakers are concerned about the rising Out-Of-Pocket (OOP) healthcare expenditures and their influence on the household economy [2]. This makes health economic evaluation is more important in the healthcare pricing and reimbursement decision-making process.

Household Out-Of-Pocket healthcare expenditures and lack of alternative payment systems, such as insurances are features of the healthcare financing system in low-middle income countries (LMIC) [3]. Many people in low-middle-income countries depend on household Out-Of-Pocket healthcare expenditures any time they receive healthcare services, and unfortunately, they are not protected from financial hardships [4]. Hence, household Out-Of-Pocket healthcare expenditure at a service point is considered an inequitable financing method in the healthcare system [5].

Globally, annually, about 150 million people from 44 million households are impacted by the economic burden of household Out-Of-Pocket healthcare expenditures and nearly more than 100 million from 25 million households are placed into poverty through household Out-Of-Pocket healthcare expenditures [6]. The utilization of healthcare services is impacted by household Out-Of-Pocket healthcare expenditures particularly, people in LMIC, in which on average, household OutOf-Pocket healthcare expenditures comprise about $40 \%$ of healthcare expenditure [7]. Furthermore, in LMIC average household Out-Of-Pocket healthcare expenditure per individual has risen by $66 \%$ between 2000 and 2017 [8]. The increased Out-Of-Pocket, particularly in developing countries, can cause economic difficulty, contribute to impoverishment, force households to cut their basic necessities, income loss, and force the household to sell their assets to finance needs for healthcare services [9]. Moreover, poor households may not even be able to afford to seek essential healthcare and they remain trapped in a vicious circle of illness and poverty $[9,10]$.
In Ethiopia, the burden of household Out-Of-Pocket healthcare expenditures is a significant public health problem and accounts for about 34\% (one-third) of total healthcare expenditure, and is one of the highest in the world and is associated with a lack of health insurance coverage and inadequate coverage [11]. Moreover, household Out-Of-Pocket healthcare expenditure is an obstacle for households in accessing healthcare services, however, it is one of the indices to evaluate and address the level of financial risk protection in healthcare systems, and of concern to policymakers and is a key priority in the global health policy agenda and is an indicator of progress toward the Sustainable Development Goals (SDGs) for universal health coverage [11].

In this systemic review and meta-analysis, we developed and applied a conceptual framework that captures elements of our general objective to provide data that could support improvements in healthcare-seeking and reduce financial hardship during healthcare-seeking [12]. Therefore, this study centred on core conceptual domains on identifying problem areas or outcome variables (i.e., the burden of household Out-Of-Pocket healthcare expenditures). The resulting conceptual framework outlines the interconnected factors with our outcome variable such as socioeconomic and demographic factors: (i.e., age, income/household total expenditure, place of residence, educational status, occupation, marital status, and family size); environmental factors (i.e., travel time or distance to health facility and type of health facility visited); having a chronic illness or any illness, and having health insurance.

In Ethiopia, studies indicated that the burden of household Out-Of-Pocket healthcare expenditures was high and has shown a significant increment, indicating $2 \%$ of households are facing financial hardship, and this per cent would likely increase with greater health services utilization [13]. In recent years, $46 \%$ of rural households in Ethiopia, that sought healthcare faced catastrophic healthcare expenditure at the threshold of $10 \%$ of total household expenditure, or $74 \%$ at a $40 \%$ nonfood expenditure, and $92 \%$ of households that sought 
healthcare were pushed further into extreme poverty due to household out-of-pocket healthcare expenditures [14]. Yet, in Ethiopia, Out-Of-Pocket healthcare expenditure could be an obstacle and still create barriers and difficulties for households to healthcare access and may delay or forgo needed healthcare use.

Moreover, to the best of our knowledge, no systematic review and meta-analysis have been carried out to report a consolidated burden of household Out-Of-Pocket healthcare expenditures in Ethiopia. Yet, at the national level, study findings are highly dispersed and inconsistent. We used almost all national representative available data. Evidence on the association between socio-demographic factors, illness status, and household Out-OfPocket healthcare expenditures highlights vulnerable households who should be the priority in financial protection policy in Ethiopia.

Furthermore, the burden of household Out-Of-Pocket healthcare expenditures seemed to be high and large numbers of households are suffering from financial hardship in Ethiopia [13]. In this context and within the current literature, this study advances research by generating novel national evidence (pooled estimates) on the burden of household Out-Of-Pocket healthcare expenditures and its influencing factors in Ethiopia. The findings of this study could be input and would help as a base for evidence-based policy intervention and policy practice, and to formulate recommendations that could potentially promote citizen-based healthcare service utilization audit and strengthen community-based health insurance in Ethiopia [15]. In addition, our study is important because it assesses the burden of household Out-OfPocket healthcare expenditures, which is one of the monitoring indicators for healthcare financing schemes in the country. The study would also be of paramount importance for researchers to do in related topics. Therefore, in this systemic review and meta-analysis, the purpose was to provide a comprehensive understanding of the burden of financial hardship for healthcare-seeking in Ethiopia and to advance research by generating novel national evidence (pooled estimates) household Out-Of-Pocket healthcare expenditures and their influencing factors with the aim to assess the burden of household Out-OfPocket healthcare expenditures in Ethiopia. The review question was: what was the extent of the burden of OutOf-Pocket healthcare expenditures that were associated with poor socioeconomic status, compared to the rich, in Ethiopian households with illnesses?

\section{Methods}

\section{Reporting and registration of the protocol}

The report of this systematic review and meta-analysis was written using an updated PRISMA 2020 guideline (i.e, Preferred Reporting Items for Systematic Review and Meta-Analysis) [16]. The details of this systematic review and meta-analysis have been registered on the PROSPERO database (i.e., International Prospective Register of Systematic Reviews) with reference number ID: CRD42021255977 [17]. The completed checklist has been provided as supplementary material (Additional file 1).

\section{Eligibility criteria}

We reviewed articles using defined inclusion and exclusion criteria. Briefly, it would be articles that contain information answering our research question. But, the most important is that it should be clear and sufficient information, including positive or negative, to answer the question.

\section{Inclusion criteria}

Study type All observational articles (cross-sectional, and cohort or longitudinal) and grey literature reporting the target outcomes, i.e., household Out-Of-Pocket healthcare expenditures and their determinants in Ethiopia were included.

Setting Both community and institutional-based articles conducted in Ethiopia were included.

Language Articles written and published in the English language were included.

Population The participants were Ethiopian households or individuals with and without experience of OutOf-Pocket healthcare expenditures.

Publication status Articles available as full-text, peerreviewed, and published articles were included.

Publication status All published articles.

Publication year There was no restriction on the publication period.

Publication date We included articles published until 31 June 2021.

\section{Exclusion criteria}

Articles that were unrelated or duplicated or overlapping data, articles that didn't report full texts or were unavailable in full texts, articles with data not reliably extracted, articles that didn't report household OutOf-Pocket healthcare expenditures, articles with different outcomes of interest, studies with a methodological 
score less than $50 \%$, with randomized controlled trials, systematic review, case report, case series, editorials, author response, theses, and books, articles that had no abstracts or abstract-only papers as preceding papers, conference, editorial, and commentaries, articles conducted in nonhuman subjects, articles that qualitative in design, and those not published in the English language were excluded.

\section{Information sources}

For this systematic review and meta-analysis, a primary literature search was carried out using PubMed/Medline and Google scholar electronic databases and a manual direct Google search engine from June 1 to 31, 2021.

\section{Search strategy}

To ensure consistency across articles and to ensure comprehensiveness, a common and comprehensive fourstage systematic review of primary studies was employed. An initial search was carried out on PubMed/Medline and Google scholar electronic databases, followed by an analysis of the text words contained in the title/abstract and indexed terms. A second search combined free text words and indexed terms with Boolean operators and key terms: (prevalence OR incidence OR burden) AND household Out-Of-Pocket healthcare expenditures OR Out-Of-Pocket healthcare expenditures OR catastrophic healthcare expenditures OR impoverishing healthcare expenditures AND Ethiopia. In other words, (financial risk OR financial catastrophe OR health equity) AND (factors OR risk factor OR risk OR determinant) AND household Out-Of-Pocket healthcare expenditures AND Ethiopia. The third search used reference lists of all identified eligible articles to identify other additional pertinent articles to this review. Finally, an additional search was conducted on the Google search engine manually. The primary search strategy was largely limited to English language publications as deemed appropriate based on a review of the primary and secondary search results. Articles retrieved from various electronic databases and Google search engines were exported to EndNote reference manager software version X7 (Thomson Reuters, Stamford, CT, USA) where duplicate articles could be identified and removed. Some duplicates were also addressed manually due to variations in reference styles across sources. We kept a log of all reviewed articles.

\section{Study records}

\section{Data management}

We adhered to an updated PRISMA 2020 guideline [16] to assess the identified articles by their titles, abstracts, as well as full-text contents against the predefined eligibility criteria.

\section{Selection process}

During the selection process, the selection of articles was carried out by two independent reviewers in two phases: the first phase was that for the eligibility of the studies, unnecessary data was excluded by reading, screening, or reviewing the titles and abstracts of each article yielded by the comprehensive search. The second phase was that after reading the abstracts of the articles that were potentially relevant to this review, we reviewed the full texts against the selection criteria. During this article selection process, articles; which were not fully accessed, unclear, vague, incomplete, or any relevant information was missing from the reviewed articles; were excluded. However, before excluding the articles, the corresponding author of the study was contacted via e-mail at least two attempts to retrieve the missing information every 2 weeks apart.

\section{Data collection process /data extraction or abstraction/}

Relevant data from each study was extracted in duplicate by two independent reviewers from source documents using a customized, standardized, beforehand piloted data collection form in Microsoft Excel. After screening, all full-text articles were assessed for eligibility and were included in a summary table (Additional file 2). Subsequently, both reviewers examined the extracted data and determine the level of evidence. Any differences in opinion between the two independent reviewers were resolved consensus-based discussion. If insufficient, this was followed by a referral to a third reviewer to fix the matter at hand.

As it is recommended by PRISMA guideline [18], pre-specified data elements were extracted from each article for primary outcome: including quantitative findings such as the number of participants (households / individuals) who experienced Out-Of-Pocket healthcare expenditures ('Yes'), and those who did not experience Out-Of-Pocket healthcare expenditures ('No'), total households/individuals (n), and AOR (95\% CI) were presented on the column of the data collection form. The primary outcome also included qualitative information: like the name of the first author (principal author), publication year, title and journal, study area (country and region), study design, year of study, setting/location, sample size, response rate, and the tool also presented on the data collection form. In the meantime, for the secondary outcome (predictors), the data included socio-demographic variables (gender mean of age of the participants, and socioeconomic status of households/individuals) if at least two or more studies reported them as a predictor. We selected these variables because they are the most frequently reported predictors by the sample studies identified for this meta-analysis. For each predictor, to calculate the odds ratio, we extracted the data from the 
primary studies in the form of two by two tables. Any deviations from the central predetermined inclusion and exclusion criteria were noted and justified. Whenever variations of extracted data were observed, all the steps were repeated.

\section{Data items /definition of variables/}

For the aim of this study, a systematic review was defined as a review of the available evidence on a formulated question using an explicit plan and systematic search strategy to identify, select, critically appraise, and combine relevant and reliable primary research, and to extract and analyze data from the articles that were included in the review [19]. While meta-analysis was defined as a statistical method used to pool or systematically combine, summarize, and interpret the results from more than one previous study to derive conclusions about that body of research [20]. Household total expenditure is defined as the sum of household food consumption expenditure and non-food consumption expenditures of the household. Household Out-Of-Pocket expenditures covered expenditures made by a patient or a household for care and treatment.

\section{Outcome measurement}

This systematic review and meta-analysis had two main outcomes.

\section{Primary outcomes}

The primary outcomes were the burden of household Out-Of-Pocket healthcare expenditures in Ethiopia. The burden of household Out-Of-Pocket healthcare expenditures was measured using either its share of total household income or its share of total household consumption. Therefore, household Out-Of-Pocket expenditures was that made by a patient or a household for care and treatment; for example, included payments for card fees or consultation fees, medication, laboratory tests, and health facility or hospital bills where insurance does not cover the full cost of the healthcare services [21]. Household payment for utilisation of healthcare services was the summation of the household's direct medical and direct non-medical Out-Of-Pocket healthcare expenditures. A household's direct medical Out-Of-Pocket healthcare expenditures were calculated in terms of direct payment made by households to healthcare providers at the point of receiving healthcare services. This included registration/card fees, medicines, laboratory tests, etc., for outpatient visits; and for inpatient stays, bed charges at healthcare facilities.

Direct costs are costs associated with card fees /consultation, diagnostic workup medications, and transportation. Household's direct medical Out-Of-Pocket healthcare expenditures have excluded any prepayment for healthcare services, i.e. taxes or insurance.

Household's direct non-medical Out-Of-Pocket healthcare expenditures were calculated in terms of payments related to transportation, and daily living payments including accommodation, and food for the accompanying household members or caregivers, and additional expenses for the caregiver during outpatient and inpatient visits [22]. Thus, the burden of household Out-OfPocket healthcare expenditure was calculated as its share of total household income or its share of total household consumption [21] of households/participants who have been included in the study (sample size) multiplied by 100.

Catastrophic health expenditure, households whose financial contributions to the health care exceeded $10 \%$ of total household expenditure or $40 \%$ of non-food household expenditure or income were considered as exposed to catastrophic healthcare expenditures.

\section{Secondary outcomes}

The risk factors of the burden of household Out-OfPocket healthcare expenditures in different regions of the country were secondary outcomes, such as socioeconomic and demographic factors (i.e., age, income/household total expenditure, place of residence, educational status, occupation, marital status, and family size); environmental factors (i.e., travel time or distance to health facility and type of health facility visited; and health insurance); and having a chronic illness or any illness.

\section{Risk of bias in individual studies /quality assessment/}

To evaluate the quality of the articles, the trustworthiness and relevance of the results of published articles (reporting, external and internal validity) were evaluated using the Joanna Briggs Institute's standardized critical appraisal tools [23] (Additional file 3). Articles with an average of greater than $50 \%$ (four out of eight) scores for cross-sectional studies and 50\% (six out of twelve) scores for cohort studies in Joanna Briggs Institute's standardized critical appraisal were considered as low risk and included in the study. Moreover, the quality of those articles that passed the Joanna Briggs Institute's critical appraisal, was also further evaluated using a modified version of 'The Newcastle-Ottawa Scale (NOS)' [24] (Additional file 4). 'The Newcastle-Ottawa Scale (NOS)' has three major domains and is graded out of 10 points (stars): 1) the first section assesses the methodological quality of each study and weighs a maximum of five stars; 2) the second section considers the comparability of the study and takes two stars; 3) the last part of the tool assesses outcomes with related to statistical analysis. 
To assess the trustworthiness, relevance, and quality of the articles, the following items were used to appraise, for example, for case-control studies: (1) comparable groups, (2) cases and controls matched, (3) the same criteria used for identification, (4) exposure measured in a standard, valid and reliable way, (5) exposure measured in the same way for cases and controls, (6) confounding factors identified, (7) strategies to deal with confounding factors, (8) outcomes assessed in a standard, valid and reliable way for cases and controls, (9), the exposure period of interest long enough, and (10) appropriate statistical analysis [25]. Cohort articles were also appraised by using the following items: (1) the two groups similar and recruited from the same population, (2) the exposures measured similarly to assign people to both exposed and unexposed groups, (3) the exposure measured using valid and reliable methods, (4) confounding factors identified, (5) strategies to deal with confounding factors, (6) participants free of the outcome at the start of the study, (7) the outcomes measured using valid and reliable methods, (8) follow up time reported and sufficient to be long enough for outcomes to occur, (9) follow up complete, and if not, were the loss reasons to follow up described and explored, (10) strategies to address incomplete follow up, and (11) appropriate statistical analysis [25]. For cross-sectional articles the following items were used to appraise the quality: (1) criteria for inclusion, (2) study subjects and the setting described, (3) exposure measured using valid and reliable methods, (4) standard criteria used for measurement, (5) confounding factors identified, (6) strategies to appropriate statistical analysis deal with confounding factors, (7) outcomes measured using valid and reliable methods, and (8) appropriate statistical analysis [25].

To assess the trustworthiness, relevance, and quality of economic evaluation studies, the following items were also used to appraise: (1) the question defined, (2) alternatives described, (3) costs and outcomes identified, (4) clinical effectiveness established, (5) costs and outcomes measured accurately, (6) costs and outcomes valued credibility, (7) costs and outcomes adjusted for differential timing, (8) incremental analysis of cost and consequences conducted, (9), sensitivity analysis conducted, (10) issues of concern to users included, and (11) generalizability of findings in the review [26].

\section{Data synthesis and analysis}

Selected articles were rated for level of evidence and methodological quality, information that was also included. Based on the evidence compiled, answers to the targeted questions were formulated and anonymized voting was done. A level of consensus of $80 \%$ or higher was considered to represent a strong agreement. Subsequently, study data were quantitatively synthesized.
The necessary data were extracted using a Microsoft Excel format, and then it was imported and the Metaanalysis was done by using RevMan software Version 5.4.1 [27]. Data were tabulated, and a narrative synthesis was presented. A descriptive statistical analysis was performed to summarize the extracted data. The standard error of prevalence/incidence for each original article was calculated by the binomial distribution formula.

Since the included articles may exhibit high heterogeneity, a random effect meta-analysis model was computed to determine the pooled estimate of the burden of household Out-Of-Pocket healthcare expenditures [28]. A Forest plot was used to summarize information on each study and show the estimated common effect, and all in one figure. The associated factors were qualitatively narrated or synthesized accordingly (socioeconomic and demographic factors, environmental factors, behavioural factors, and illness status). Moreover, the association between predictor variables, and household Out-OfPocket healthcare expenditures were examined.

The Cochrane's Q and $I^{2}$ statistic was used to check heterogeneity among included articles and to identify which articles contribute to the observed heterogeneity as part of outlier and influence analyses, where significant heterogeneity was assumed if the $P$-value for the $Q$ test $<0.10$ and $\mathrm{I}^{2}$ value $>50 \%$ (the values of 25,50 , and $75 \%$ represented as low, moderate, and high level of heterogeneity, respectively) [29]. However, if articles were heterogeneous $\left(\mathrm{I}^{2}>50 \%\right)$, the results of each study were narrated. However, in this study, an $\mathrm{I}^{2}$ value of less than $50 \%$ was considered to interpret the combined effect size.

Subgroup analyses (also known as moderator analyses) were carried out based on the region of studies and sample size, to assess why some studies have higher or lower true effect sizes than others or find excess variability (patterns of heterogeneity) in studies and what causes it.

Sensitivity analysis was also conducted to assess the effects of a single study on determinants of the burden of household Out-Of-Pocket healthcare expenditure [30].. For the small number of articles, it may be impossible to estimate the between studies variance with any precision. Therefore, we used a fixed-effect model for less than five articles and a random effect model for five and above articles [31]. Moreover, univariate meta-regression was conducted by taking the publication year to explain the true effect size differences in the studies (the betweenstudy heterogeneity variance), and the sample size of the studies to identify the possible source of heterogeneity.

\section{Meta-bias (es)}

Meta-bias, presence of potential publication bias, and selective reporting within articles were assessed subjectively by using a Funnel plot through a visual inspection 
of the symmetry of the amount of study heterogeneity [32].

\section{Confidence in cumulative evidence}

The level of significance was set at $95 \%$ confidence level and $P<0.05$.

\section{Results}

\section{Search results}

The search strategy retrieved 210 articles from databases and other sources. Of these initial records, 98 articles were excluded due to duplication. From the remaining 112 articles, 80 articles were excluded for reasons as their titles and abstracts did not match $(=62)$ and some articles were irrelevant to study questions $(=18)$. Therefore, 32 full-text articles were accessed, and assessed for eligibility based on the pre-set criteria, which resulted in the further exclusion of five articles primarily due to some articles were not being published in peer-reviewed journals (= three) (i.e., thesis) and some did not report outcome interest (= two). Then, 27 articles with a sample size of 331,537 participants were included to assess determinants of the burden of household Out-Of-Pocket healthcare expenditures. Of these, six articles were conducted at the national level [13, 33-37]. The remaining 21 articles were conducted in different parts of Ethiopia: i.e., six articles were conducted in the south regional state [14, 33-37], five articles in Amhara regional state [38-42], five articles in Addis Ababa city [43-47], three articles in Oromiya regional state [48-50], one article in Bensangual-Gumuz regional state [51], and one article in a combination of Afar and Oromiya regional states [52]. Finally, 17 articles were found to be eligible and included in the meta-analysis (Fig. 1).

\section{Characteristics of included articles}

Twenty-one articles were done by cross-sectional study design [33, 35-54], two articles by longitudinal cohort study design [14, 34], one article by a combination of retrospective and retrospective cohort study design [55], one report of national data [56], and two articles that used secondary data from a survey $[13,57]$ (Table 1). Moreover, these studies were conducted from 2005 and 2021.

\section{Risk of bias within articles}

By using Joanna Briggs Critical Appraisal Tools for review and meta-analysis for cross-sectional articles and cohort articles, those studies that had low risk were included for the review (Table 1, Fig. 2).

\section{The burden of household out-of-pocket healthcare expenditures \\ Direct out-of-pocket healthcare expenditures}

The pooled analysis of 21 studies identified that the mean direct Out-of-Pocket healthcare expenditures during utilization of healthcare services was $\$ 32$ per month in Ethiopia (95\%CI: $\$ 11.5, \$ 52.5)(\mathrm{SD}=\$ 45.1)[14,33,34,36,37$, 39-41, 43, 45-53, 55-57].

\section{Indirect out-of-pocket healthcare expenditures}

The pooled analysis of 10 studies identified that the mean indirect Out-of-Pocket healthcare expenditures during utilization of healthcare services were $\$ 15.6$ per month in Ethiopia (95\%CI: \$3.0, \$28.2) (SD = \$17.6) [33, 41, 43, 45, $47,49,52,55]$.

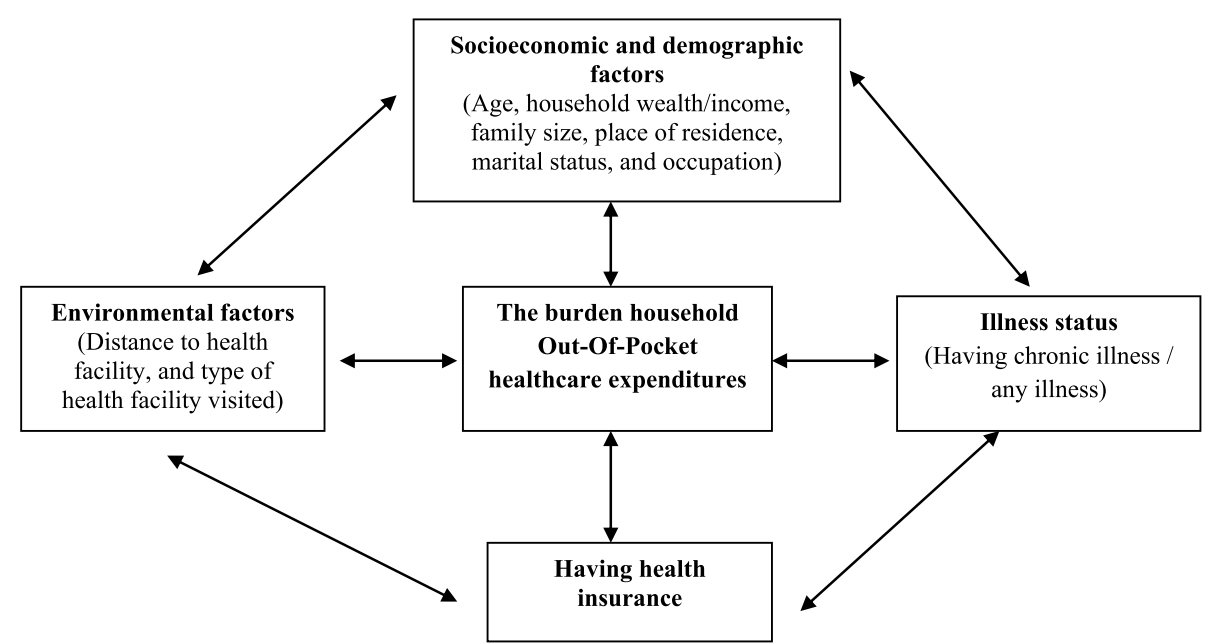

Fig. 1 The conceptual framework of determinants the burden of household Out-Of-Pocket healthcare expenditure in Ethiopia, 2021 
Table 1 Descriptive summary of 27 articles reporting the burden household Out-Of-Pocket healthcare expenditures in Ethiopia, 2021

\begin{tabular}{|c|c|c|c|c|c|}
\hline $\begin{array}{l}\text { Author (year) (reference } \\
\text { number) }\end{array}$ & Region/study area & Study design & Sample size (N) & Quality score & Quality status \\
\hline World Bank (2005) [56] & National & Report & Not specified & 6 & Low risk \\
\hline Tadele B. et al. (2005) [48] & Oromiya & Cross-sectional & 630 households & 7 & Low risk \\
\hline Wakgari D. et al. (2007) [49] & Oromiya & Cross-sectional & 2195 households & 6 & Low risk \\
\hline Pearson L et al. (2011) [53] & National & Assessment/ Cross-sectional & $\begin{array}{l}751 \text { health facilities ( } 112 \text { hos- } \\
\text { pitals and } 639 \text { health centres). }\end{array}$ & 6 & Low risk \\
\hline Tibebe Akalu, et al. (2012) [33] & South & Cross-sectional & 1015 households & 5 & Low risk \\
\hline $\begin{array}{l}\text { Mekuanenet G. et al. (2015) } \\
\text { [38] }\end{array}$ & Amhara & Cross-sectional & 467 employees & 7 & Low risk \\
\hline Getahun B. et.al. (2016) [43] & Addis Ababa & Cross-sectional & 604 patients & 7 & Low risk \\
\hline Tolla MT. et.al. (2017) [44] & Addis Ababa & Cross sectional & 625 patients & 6 & Low risk \\
\hline Memirie ST. et.al. (2017) [55] & National & $\begin{array}{l}\text { Retrospective and Prospective } \\
\text { cohort }\end{array}$ & 686 patients & 6 & Low risk \\
\hline Bedane SN et.al. (2018) [45] & Addis Ababa & Cross-sectional & 422 patients & 7 & Low risk \\
\hline Mekonen AM. et.al (2018) [39] & Amhara & Cross-sectional & 454 households & 5 & Low risk \\
\hline Fitsum S. et al. (2018) [40] & Amhara & Cross-sectional & 346 patients & 8 & Low risk \\
\hline Abyot A. et al. (2018) [34] & South & Longitudinal & 735 patients & 7 & Low risk \\
\hline Hailemichael Y. et.al (2019) [35] & South & Comparative cross-sectional & 579 households & 7 & Low risk \\
\hline $\begin{array}{l}\text { Hailemichael Y. et.al. (2019) } \\
\text { [36] }\end{array}$ & South & Comparative ross-sectional & 257 households & 7 & Low risk \\
\hline Biniam G. et al. (2019) [37] & South & Cross-sectional & 812 women & 7 & Low risk \\
\hline Amelewerk A. et al. (2019) [46] & Addis Ababa & Cross-sectional & 422 patients & 7 & Low risk \\
\hline Miljeteig I. et al. (2019) [54] & National & Survey/ Cross-sectional & 647 physicians & 8 & Low risk \\
\hline Obse AG. et.al. (2020) [57] & National & $\begin{array}{l}\text { Data from the Ethiopian } \\
\text { Household Consumption } \\
\text { Expenditure Survey (HCES) } \\
2010 / 11\end{array}$ & $\begin{array}{l}\text { 10,368 rural and 17,664 urban } \\
\text { households }\end{array}$ & 7 & Low risk \\
\hline Debelo S. et.al. (2020) [51] & Benishangul-Gumuz & Cross-sectional & 488 households & 7 & Low risk \\
\hline Mizan K. et al. (2020) [13] & National & $\begin{array}{l}\text { Data from the } 2015 / 16 \text { Ethio- } \\
\text { pian household consumption } \\
\text { and expenditure and welfare } \\
\text { monitoring surveys }\end{array}$ & 30,229 households & 6 & Low risk \\
\hline Addisu B. et al. (2020) [50] & Oromiya & Cross-sectional & 354 patients & 7 & Low risk \\
\hline Assebe LF. et.al. (2020) [52] & Afar and Oromiya & Cross sectional & $\begin{array}{l}1006 \text { HIV and 787TB partici- } \\
\text { pants }\end{array}$ & 5 & Low risk \\
\hline Borde MT. et.al. (2020) [14] & South & Prospective cohort & 2350 participants & 7 & Low risk \\
\hline Kasahun GG. et.al. (2020) [47] & Addis Ababa & Cross-sectional & 404 participants & 6 & Low risk \\
\hline Tsega G. et al. (2021) [41] & Amhara & Cross-sectional & 422 participants & 7 & Low risk \\
\hline Yohannes S. et al. (2021) [42] & Amhara & Cross-sectional & 302 chronically ill patients & 6 & Low risk \\
\hline
\end{tabular}

\section{Catastrophic healthcare expenditure}

The pooled analysis of 14 studies identified that the mean catastrophic healthcare expenditures at $10 \%$ of threshold during utilization of healthcare services was $40.1 \%$ in Ethiopia (95\%CI: 28.7, 52.2\%) (SD=20.4\%) [13, 14, 35, $36,38-42,44,47,48,50-52,56]$.

\section{Coping mechanisms}

The pooled analysis of 11 studies identified that the common coping mechanisms during utilization of healthcare services in Ethiopia were a sale of household assets, support from family and relatives, and loan: $40.1 \%$ (95\%CI: 28.7, 52.2\%) $(\mathrm{SD}=20.4 \%)[14,33,36,38,41,43$, $44,47-49,52]$.

\section{Meta-analysis}

As shown in the forest plot, a quantitative pooled analysis of 14 included articles revealed that the pooled burden household Out-Of-Pocket healthcare expenditures in Ethiopia were strongly positively associated with household economic status. The odds of facing 


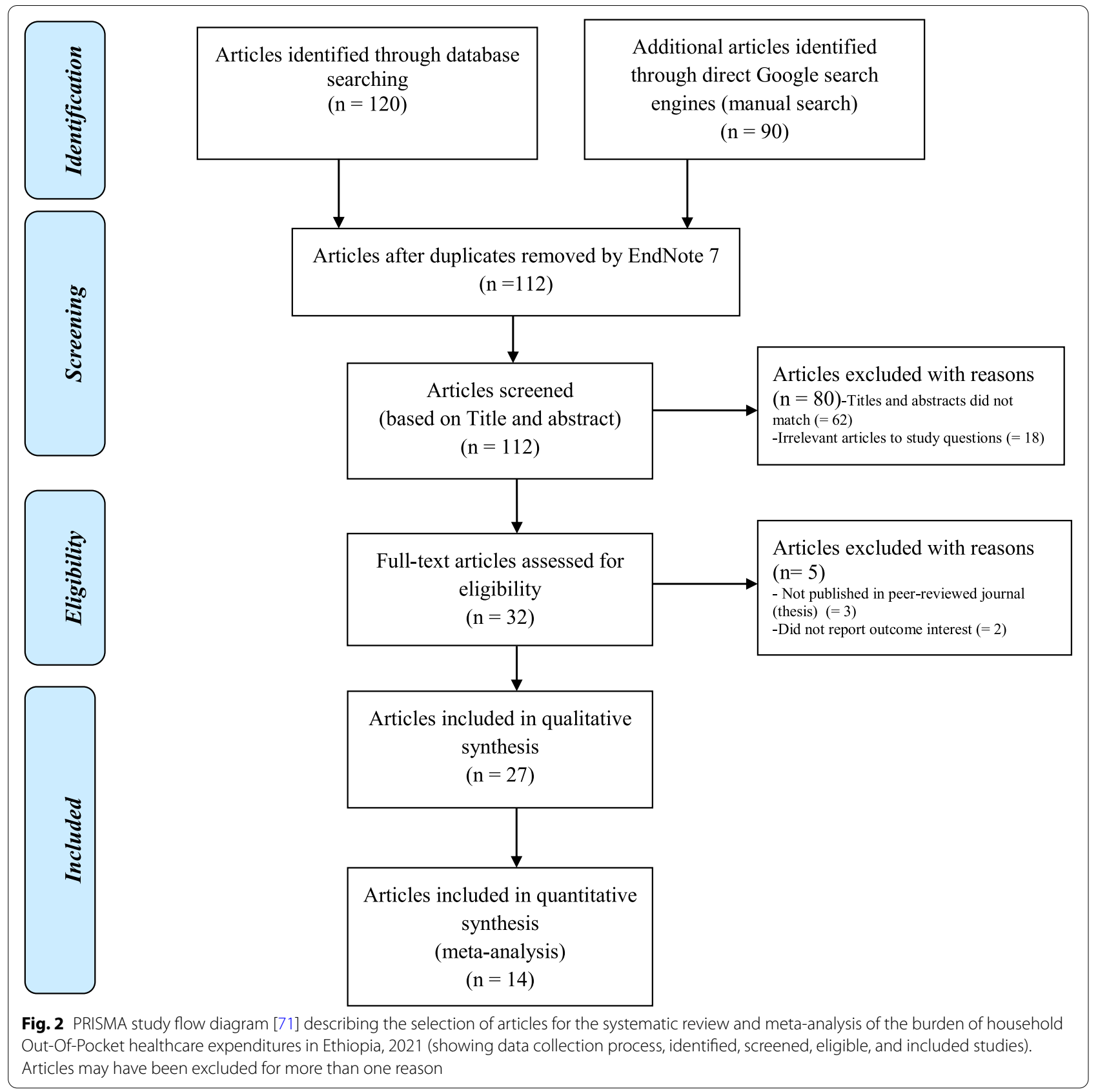

Out-Of-Pocket / catastrophic healthcare expenditures among the poorest quintile was about three times that of the richest $(\mathrm{AOR}=3.09,95 \% \mathrm{CI}: 1.63,5.86) p$-value $<0.001$, (Table 2). Nonetheless, extreme heterogeneity was exhibited across the studies and uncovered by $P$-value for Cochrane's $Q$ test $(p$-value $<0.001)$ and $\mathrm{I}^{2}$ statistic $\left(\mathrm{I}^{2}=95 \%\right)$. As a result, a random effect model was employed to estimate the pooled burden of household Out-Of-Pocket healthcare expenditures in Ethiopia.

\section{Factors associated with the burden of household out-of-pocket healthcare expenditures}

In this study, socioeconomic and demographic factors; environmental factors; illness status; and healthcare-seeking behaviour (i.e., insured households) were 
Table 2 The forest plot of the pooled estimates of the burden household Out-Of-Pocket healthcare expenditures in Ethiopia, 2021

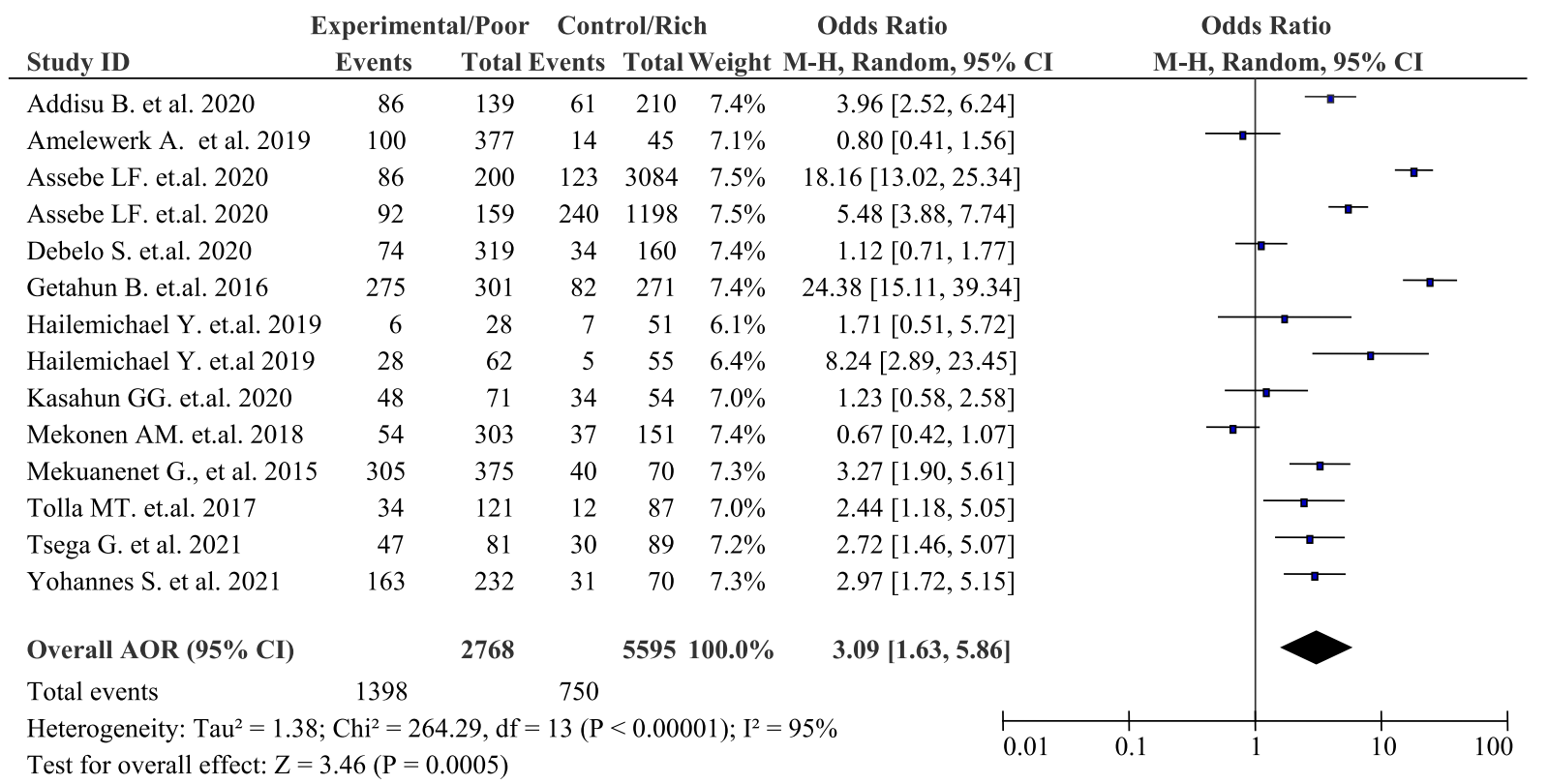

independent predictors of the burden of household Out-Of-Pocket healthcare expenditures in Ethiopia.

The factors such as socioeconomic and demographic factors (i.e., age, household wealth/income, family size, place of residence, marital status, and occupation); environmental factors (i.e., distance to health facility, and type of health facility visited); and having health insurance, exhibited that $P$-value for the Cochrane's $Q$ test $<0.10$ and $\mathrm{I}^{2}$ statistic $>50 \%$ and this indicated that the included articles were heterogeneous. However, the result of each factor was narrated.

However, for factors such as socioeconomic and demographic factors (i.e., educational status) and illness status (i.e., having a chronic illness / any illness) exhibited that the Cochrane's Q test $>0.10$ and $\mathrm{I}^{2}$ statistic $<50 \%$ and this indicated that the included articles were not heterogeneous; therefore, the combined effect size of these two factors was further interpreted.

\section{Socioeconomic and demographic factors}

The pooled analysis of four studies identified that age increased the probability of Out-Of-Pocket / catastrophic healthcare expenditure (AOR 1.02, 95\% CI: 0.98, 1.05) $[36,42,44,47]$ (Table 3). Age <30 years (AOR 7.74, 95\% CI: $0.94,63.62 ; P=0.01)$ was associated with catastrophic healthcare expenditure [42]. In other words, increasing catastrophic healthcare expenditure with age could be attributed to illness complications [47].

The pooled analysis of seven studies disclosed that household wealth / income was positively associated with the burden of household Out-Of-Pocket / catastrophic healthcare expenditure (AOR 2.58, 95\% CI: 1.31, 5.06) (Table 4). Poor households were 2.4 times (AOR =2.417; CI: $1.079,5.413)$ more likely to encounter catastrophic healthcare expenditure as compared with that of rich households [41]. Income level was strongly negatively associated with catastrophic healthcare expenditure. The odds of facing catastrophic healthcare expenditure

Table 3 Age as a factor in four articles reporting the burden household Out-Of-Pocket healthcare expenditures in Ethiopia, 2021

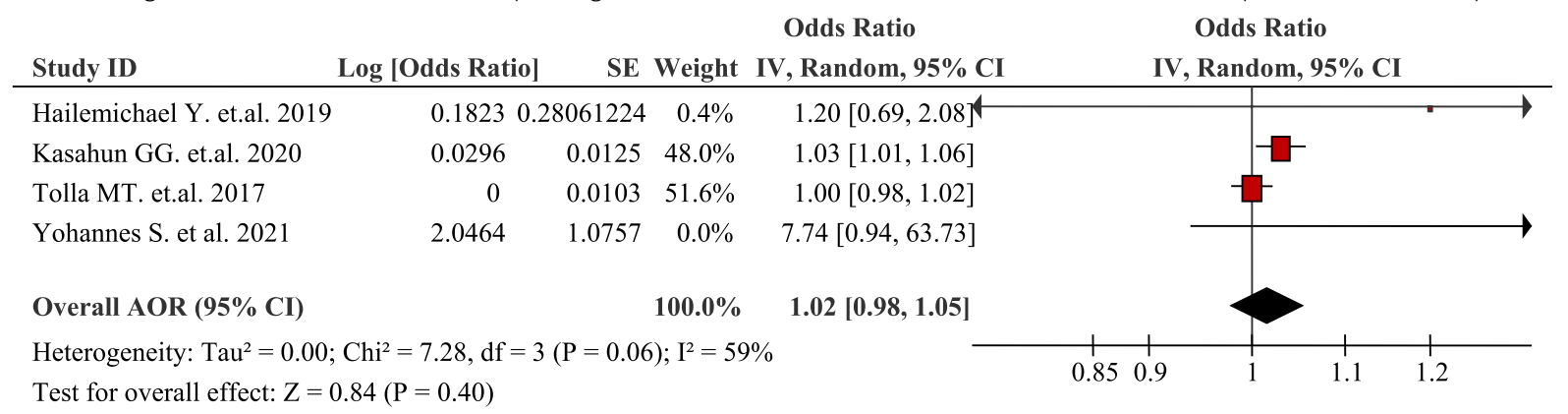


Table 4 Household wealth / income as a factor in seven articles reporting the burden household Out-Of-Pocket healthcare expenditures in Ethiopia, 2021

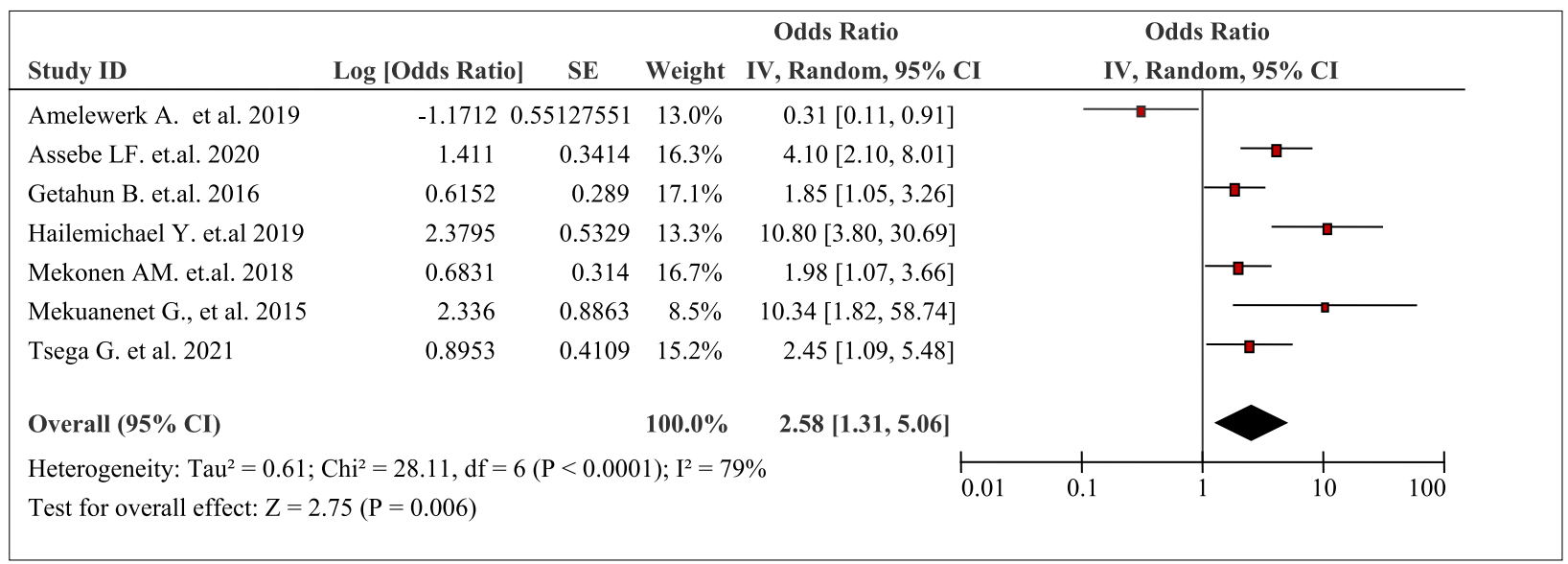

among the poor households was about 60 times that of the richest $(\mathrm{OR}=58.62,95 \% \mathrm{CI}: 16.2,208.0)$ [44].

The pooled effects of five studies revealed that household size / family size was one of the factors for the burden of household Out-Of-Pocket / catastrophic healthcare expenditures (AOR 0.89, 95\% CI: 0.60, 1.32) (Table 5). There was a linear relationship between family size and catastrophic healthcare expenditure [44]. The cost of illness increased with an increase in family size, where the cost was higher in patients with family sizes of 4-6.

(AOR 1.20, 95\% CI: 0.84,1.72) compared to patients with family size of $1-3$ [50].

The pooled analysis of five studies displayed that place of residence was positively associated with the burden of household Out-Of-Pocket / catastrophic healthcare expenditures (AOR 3.02, 95\% CI: 1.39, 6.57) (Table 6). Dwelling in rural areas, in the case of cardiovascular patients (AOR 3.25; 95\%CI: 1.79, 5.90) and the case of tuberculosis patients (AOR 3.15; 95\%CI: 1.65,
6.03) was associated with household Out-Of-Pocket or catastrophic healthcare expenditures [43, 44].

The pooled effects of three studies showed that educational status was associated with the burden of household Out-Of-Pocket / catastrophic healthcare expenditures (AOR 0.92, 95\% CI: 0.87, 0.97) (Table 7). Patients with no formal education have a higher total cost of hypertension illness (AOR 0.93; 95\%CI, 0.88, 0.98) [50] and have a higher pre-and post-diagnosis cost of tuberculosis patients (AOR 0.87; 95\%CI, 0.77, 0.97) [34] compared to patients with a primary education level.

The pooled analysis of three studies revealed that marital status was associated with the burden of household Out-Of-Pocket / catastrophic healthcare expenditures (AOR 10.25, 95\% CI: 0.92, 114.21) (Table 8). Marital status was associated total Out-Of-Pocket healthcare expenditures (AOR 0.20, 95\%CI: 0.19, 0.20) [46]. However, being unmarried was found to be associated with higher median total cost (AOR 1.17, 95\%CI: 0.02, 55.40) [40, 46].

Table 5 Household size / family size as a factor in five articles reporting the burden household Out-Of-Pocket healthcare expenditures in Ethiopia, 2021

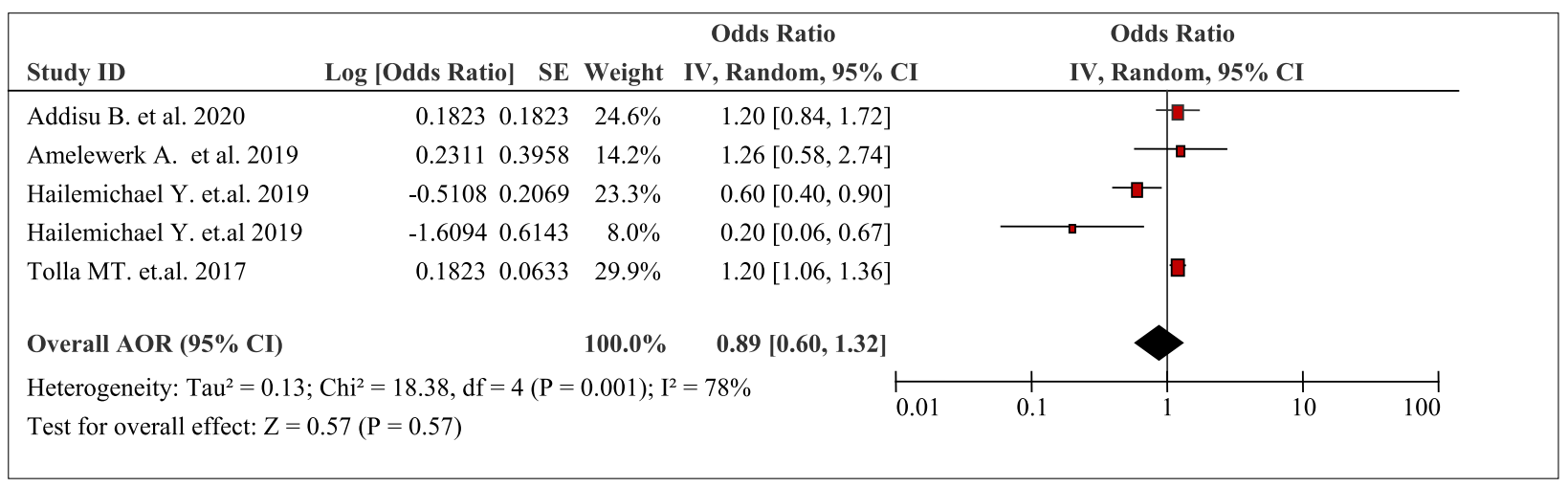


Table 6 Place of residence as a factor in five articles reporting the burden household Out-Of-Pocket healthcare expenditures in Ethiopia, 2021

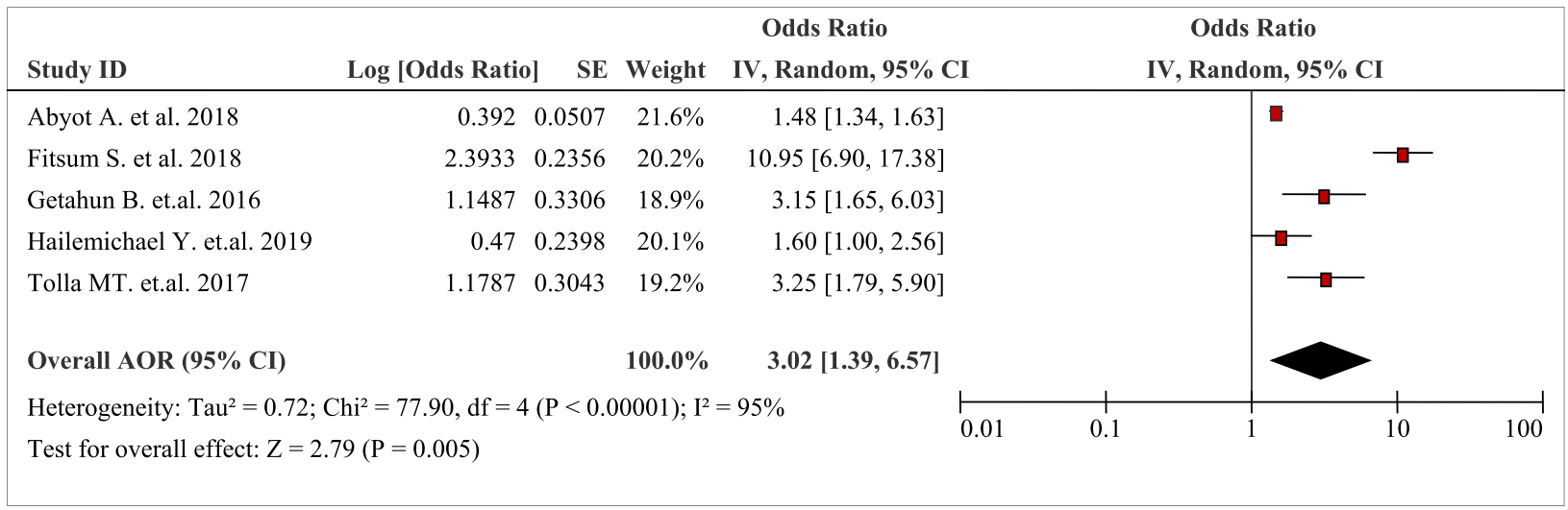

Table 7 Educational status as a factor in three articles reporting the burden household Out-Of-Pocket healthcare expenditures in Ethiopia, 2021

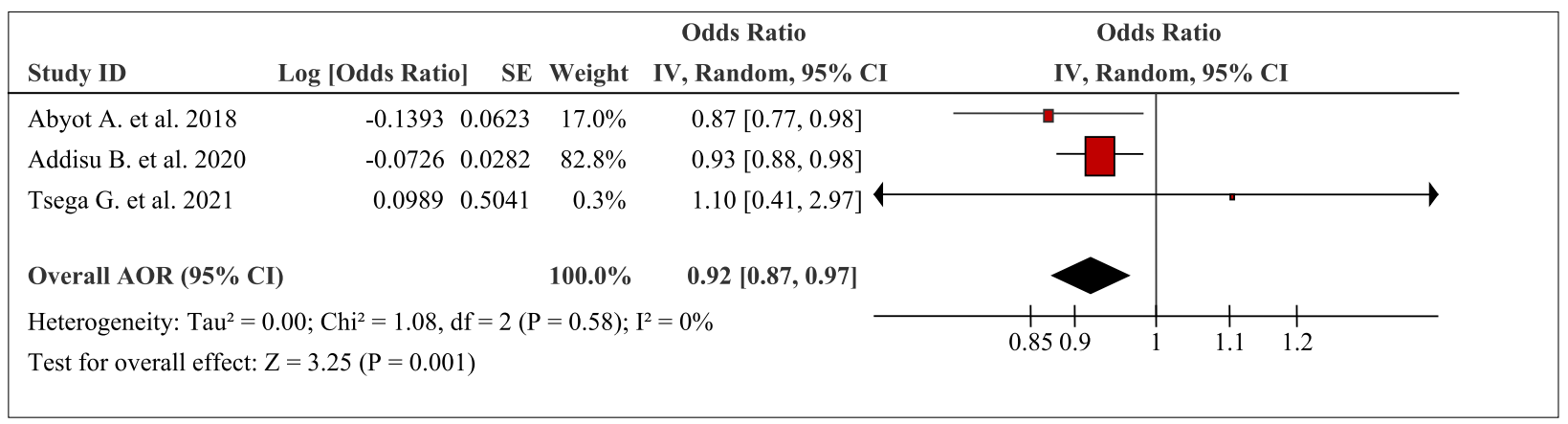

Table 8 Marital status as a factor in three articles reporting the burden household Out-Of-Pocket healthcare expenditures in Ethiopia, 2021

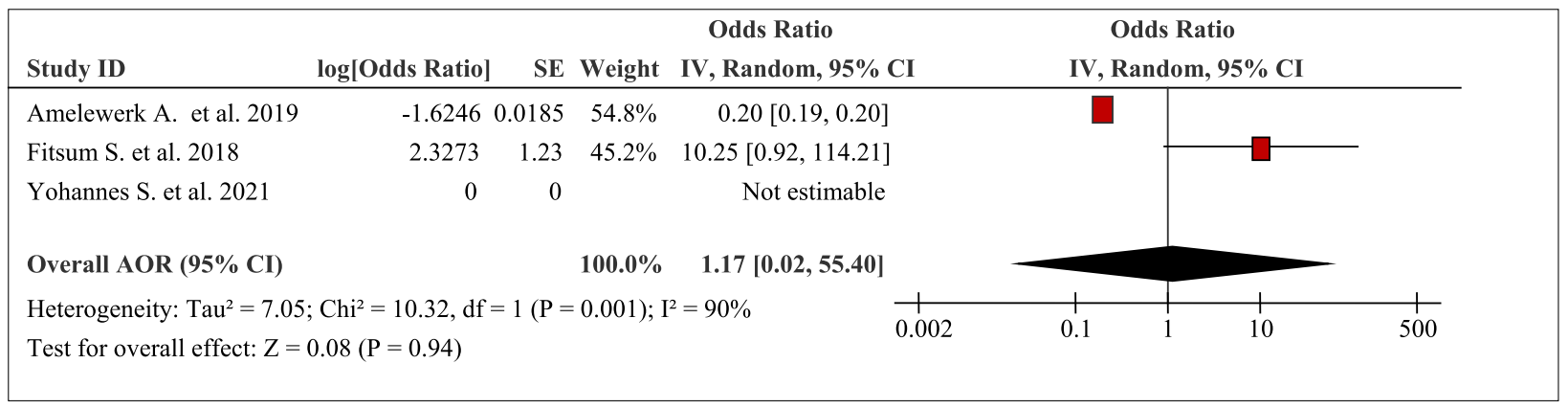

The pooled effects of three studies showed that occupation was associated with the burden of household Out-Of-Pocket / catastrophic healthcare expenditures (AOR 0.53, 95\% CI: 0.28, 1.03) (Table 9). Type of occupation of the patients was associated with total Out-OfPocket healthcare expenditures (AOR 0.84, 95\%CI: 0.83, $0.85)$ [46]. For example, households that had a member of working adults were $68 \%(\mathrm{AOR}=0.32 ; 95 \% \mathrm{CI}$ : $0.16,0.63)$ times less likely to face catastrophic healthcare expenditures compared to households who had no working adults [51].

\section{Illness status}

The pooled effects of seven studies identified that having a chronic illness / any illness was positively associated with the burden of household Out-Of-Pocket / 
catastrophic healthcare expenditures (AOR 2.23, 95\% CI: 1.77, 2.81) (Table 10). The odds of facing catastrophic healthcare expenditures among hospitalized subjects was about eight times that of the non-hospitalized subjects (OR $=8.39,95 \% \mathrm{CI}: 4.24,16.59)$ [44]. Moreover, household members with any chronic illnesses were 3.93 (AOR 3.93, 95\%CI: 1.78, 9.14) times more likely to encounter catastrophic healthcare expenditures than household members without chronic illnesses [51].

\section{Environmental factors}

The pooled effects of two studies showed that distance to health facilities was associated with the burden of household Out-Of-Pocket / catastrophic healthcare expenditures (AOR 0.06, 95\% CI: 0.00, 18.53) (Table 11).

Table 9 Occupation as a factor in three articles reporting the burden household Out-Of-Pocket healthcare expenditures in Ethiopia, 2021

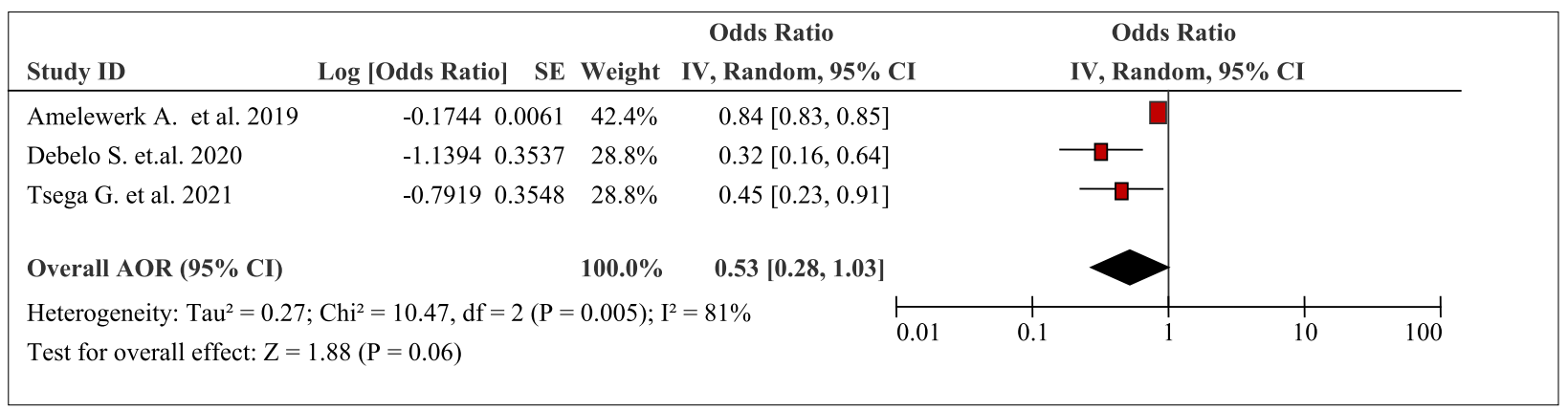

Table 10 Having chronic illness / any illness as a factor in seven articles reporting the burden household Out-Of-Pocket healthcare expenditures in Ethiopia, 2021

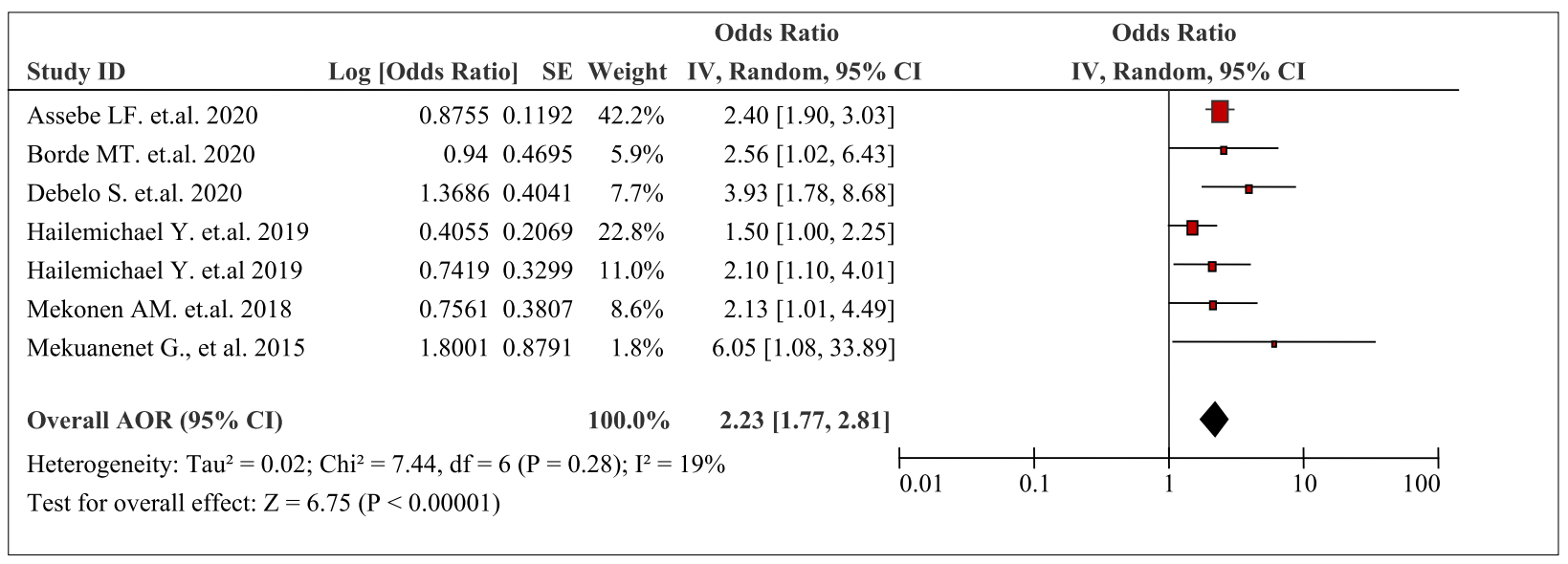

Table 11 Distance to a health facility as a factor in two articles reporting the burden household Out-Of-Pocket healthcare expenditures in Ethiopia, 2021

Odds Ratio

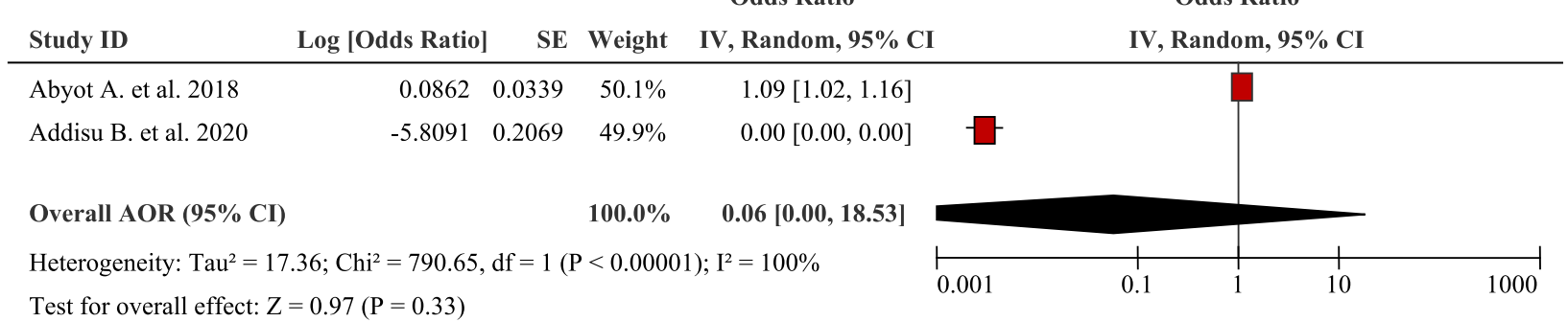


Travel time to treatment centre beyond $1 \mathrm{~h}$ predicted increased total patient cost of TB care (AOR 1.09, 95\% CI: 1.02, 1.16) [34]. Moreover, distance from the hospital $(\geq 10 \mathrm{~km})$, was the predictor of Out-Of-Pocket/catastrophic healthcare expenditures during hypertension [50].

The pooled analysis of four studies pointed out that type of health facility visited was positively associated with the burden of household Out-Of-Pocket / catastrophic healthcare expenditures (AOR 4.44, 95\% CI: $0.92,21.40$ ) (Table 12). Seeking healthcare in private hospitals increased the odds of catastrophic healthcare expenditures by 20 fold (OR $=20.7,95 \%$ CI: 10.2, 42.04) compared with public hospitals [44].

\section{Health seeking behaviour}

The pooled effects of two studies illustrated that insured households were less likely to experience household Out-Of-Pocket / catastrophic healthcare expenditures (AOR 0.70, 95\% CI: 0.05, 9.41) (Table 13). For example, insured households were $81 \%$ times less likely to incur catastrophic health expenditure $(\mathrm{AOR}=0.19,95 \% \mathrm{CI}$ : 0.11-0.33) compared with non-insured households [39]. Moreover, households with a health insurance scheme have protection from catastrophic healthcare expenditures (AOR 2.7; 95\% CI 1.10 to 6.63) [52].

\section{Subgroup analysis}

Subgroup analysis was performed to resolve study variations. In this meta-analysis, we performed subgroup analysis based on the year of publication with heterogeneity. Based on the subgroup analysis, the odds of the estimated pooled burden of household Out-Of-Pocket healthcare expenditures in Ethiopia was higher in articles published in the year after 2019 (AOR 3.95, 95\%CI 1.70, 9.18) than the year before and in 2019 (AOR 2.55, 95\%CI $0.91,7.15)$ (Table 14).

Here, the $p$-value of the subgroup for the articles published in the year before and in 2019 was not significant ( $p$-value 0.07). However, the $p$-value of the subgroup for the articles published in the year after 2019 was significant ( $p$-value 0.001). This indicated that the two subgroups were not identical. Yet, a test for subgroup differences was done to see the difference between the two groups. However, the test for subgroup differences was not statistically significant ( $p$-value 0.52 ). This indicated that there was no publication difference in the two subgroups. Moreover, the presence of high heterogeneity was dependent on the publication year (Table 14).

\section{Sensitivity analyses}

Sensitivity analysis was employed to remove inferior quality articles and to identify possible outlying articles

Table 12 Type of health facility visited as a factor in four articles reporting the burden household Out-Of-Pocket healthcare expenditures in Ethiopia, 2021

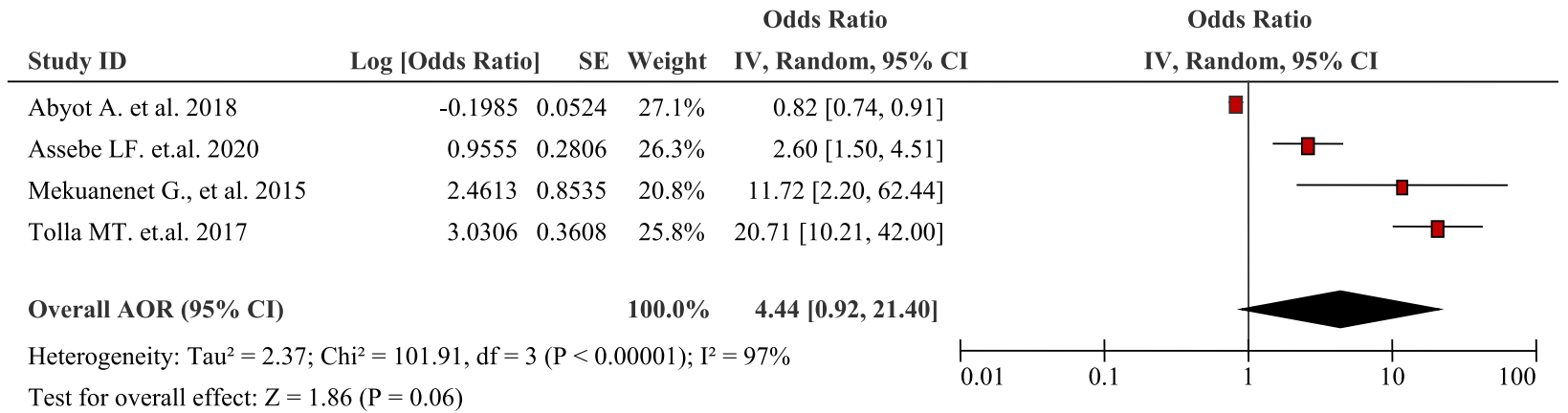

Table 13 Being insured household as a factor in two articles reporting the burden household Out-Of-Pocket healthcare expenditures in Ethiopia, 2021

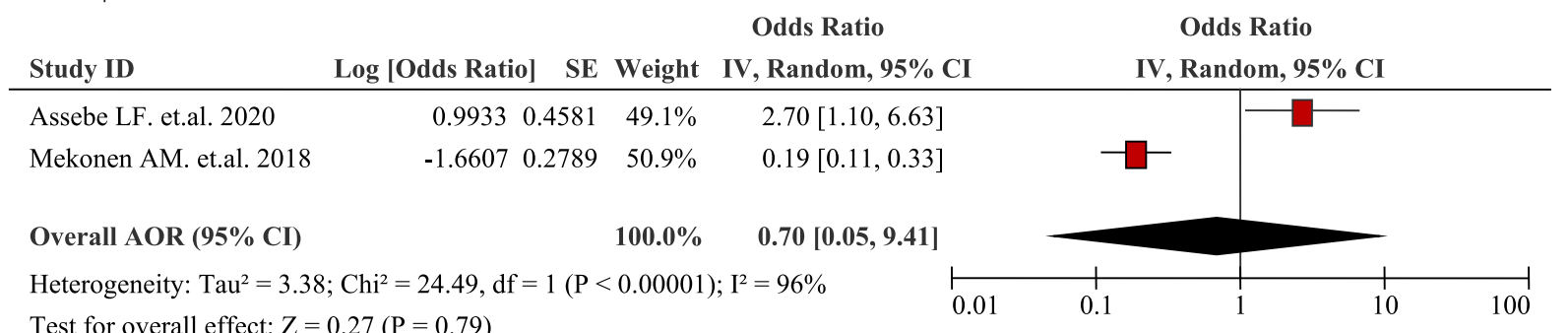


Table 14 Subgroup analysis of the pooled estimate of the burden of household Out-Of-Pocket healthcare expenditures in Ethiopia, 2021 using AOR, 95\%Cl, the $p$-value for $X^{2}$, and heterogeneity estimate among Ethiopian households or individuals with OOP / CHE

\begin{tabular}{|c|c|c|c|c|}
\hline Subgroup analysis by & Characteristics & Pooled estimate (AOR, 95\%Cl) & $\left(p\right.$-value for $\left.X^{2}\right)$ & $1^{2}$ \\
\hline \multirow[t]{2}{*}{ Year of publication } & Before and at 2019 & $2.55(0.91,7.15)$ & $p$-value, 0.001 & $95 \%$ \\
\hline & After 2019 & $3.95(1.70,9.18)$ & $p$-value, 0.001 & $96 \%$ \\
\hline \multicolumn{5}{|c|}{ Test for subgroup differences: $X^{2}=0.41, \mathrm{df}=1,(p=0.52), P^{2}=0 \%$} \\
\hline
\end{tabular}

and the effects of a single study on the overall estimation. To check the effect of a single study on the overall outcome, we used the leave-one-out method. We excluded each study, in turn, to see if it leads to a remarkable change in the fitted random-effects model. If it happens, then the study may be considered to be influential; if not, then the study may impose little influence on the results. Therefore, in all cases, there was no observed article that exerted a significant impact on the overall estimate of the burden of household Out-Of-Pocket healthcare expenditures in Ethiopia.

\section{Publication Bias}

Failure to include all of the relevant studies that have been conducted in a meta-analysis is attributed to publication bias [58]. In addition, during the analysis of publication bias, larger studies with higher power are placed towards the top and lower-powered studies are placed towards the bottom in the funnel plot [59]. Publication bias was assessed using visual inspection of the funnel plot whether there is asymmetry or not [59]. In this review, the result indicated that studies were placed towards the top; however, the funnel plot illustrates asymmetry due to heterogeneity. Publication of studies depends on the nature and direction of their results and is more likely if the results are significant or perceived as important [58]. In this review, articles that exhibited odds ratio $<1$, odds ratio between 1 and 10, and odds ratio $>10$ were identified and included in the meta-analysis (Fig. 3). In addition, the figure illustrated that there were missing studies on the bottom left-hand side of the plot. Therefore, since most of this area contains regions of high significance, publication bias is unlikely to be the underlying cause of asymmetry.

\section{Discussion}

In this systemic review and meta-analysis, the purpose was to provide a comprehensive understanding of the burden of financial hardship for healthcare-seeking in Ethiopia and to advance research by generating novel

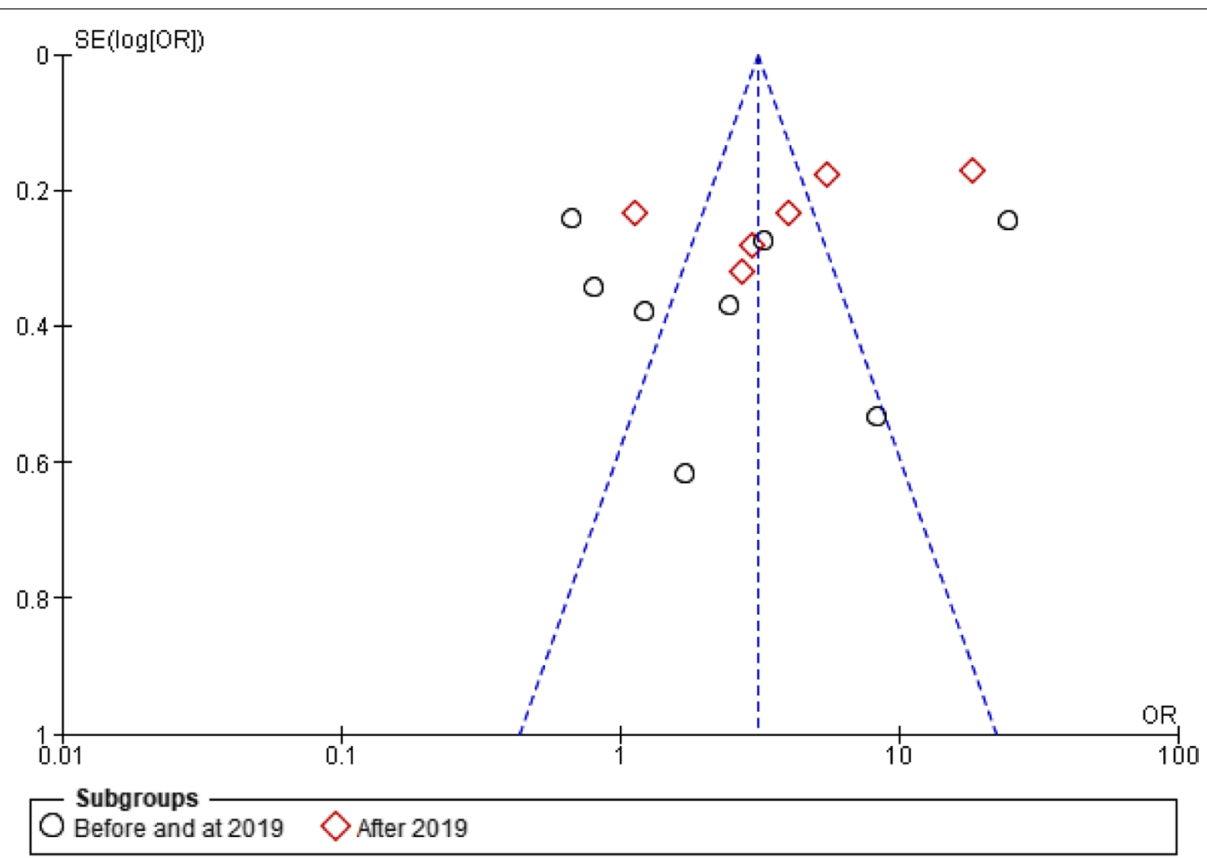

Fig. 3 Funnel plot for meta-analysis of the burden of household Out-Of-Pocket healthcare expenditures in Ethiopia, 2021 
national evidence (pooled estimates) household OutOf-Pocket healthcare expenditures and their influencing factors with the aim to assess the burden of household Out-Of-Pocket healthcare expenditures in Ethiopia. The review question was: what was the extent of the burden of Out-Of-Pocket healthcare expenditures that were associated with poor socioeconomic status, compared to the rich, in Ethiopian households with illnesses?

This systematic review and meta-analysis included 27 original studies addressing the burden of household OutOf-Pocket healthcare expenditures in Ethiopia. Regardless of the source and heterogeneity, this study revealed that the pooled burden household Out-Of-Pocket healthcare expenditure in Ethiopia was strongly positively associated with household economic status. The odds of facing Out-Of-Pocket / catastrophic healthcare expenditures among the poorest quintile were about three times that of the richest. In addition, on pooled analysis, the mean direct Out-of-Pocket healthcare expenditures were $\$ 32$ per month and the mean indirect Out-Of-Pocket healthcare expenditures were $\$ 15$ per month. About $40 \%$ of the households faced disproportionately higher catastrophic health expenditure at $10 \%$ of the threshold. Moreover, $40 \%$ of the households used a sale of household assets, support from family, or loan as the common coping mechanisms.

For example, this finding suggests that a significant proportion of Ethiopian households or individuals face catastrophic healthcare expenditure which is an obstacle for basic access to healthcare and utilization. This finding is higher than the studies conducted in Rwanda and Tanzania reported that 20.1 and $18 \%$ of the households had catastrophic health expenditure respectively [60, 61]. Similarly, the number of households categorized as having catastrophic health expenditure in Kenya was 18\% at a $30 \%$ threshold to $22.2 \%$ at a $10 \%$ threshold [62]. Yet, this finding is consistent with the findings from south Ethiopia in which $46 \%$ of households faced catastrophic healthcare expenditure at the threshold of $10 \%$ of total household expenditure [14]. The possible explanation for the observed difference might be due to socioeconomic differences between the households of Iran and Ethiopia. However, even though Out-Of-Pocket / catastrophic healthcare expenditures are increasing, countries with a prepayment system or social protection system provide better access to healthcare and are less burdened by OutOf-Pocket / catastrophic healthcare expenditures [63]. Therefore, it should be noted that other potential causes may also exist, such as lack of free healthcare in public health facilities and changes in the incidence of diseases towards more chronic illnesses.

In this review, the common influencing factors on the burden of household Out-Of-Pocket healthcare expenditures in Ethiopia were socioeconomic and demographic factors (i.e., age, household wealth / income, family size, place of residence, educational status, marital status, and occupation); environmental factors (i.e., distance to health facility, and type of health facility visited); illness status (i.e., having chronic illness / any illness); and having health insurance, however, after excluding factors with high heterogeneity, factors such as educational status and having a chronic illness/any illness were not heterogeneous; and therefore, the combined effect size of these two factors was further interpreted here.

According to previous studies, households with lower educational status are at an increased risk of incurring the burden of household Out-Of-Pocket / catastrophic healthcare expenditures $[64,65]$. In this review, educational status was associated with the burden of household Out-Of-Pocket / catastrophic healthcare expenditures. This is also evidenced by other studies from Ethiopia indicating that patients with no formal education have a higher total cost of hypertension illness [50] and have higher pre-and post-diagnosis costs of tuberculosis patients compared to patients with a primary educational level [34]. These findings are consistent with a study from China indicating households someone with higher education are less likely to suffer catastrophic health expenditure [66]. Household heads with little education increased the odds of catastrophic health expenditure within the poor [67]. This requires an integrated, poverty-oriented social policy approach is needed to address these factors and alleviate the burden of household OutOf-Pocket / catastrophic healthcare expenditures.

In this review, concerning the presence of chronic illness / any illness in the household was found to be statistically significant with household Out-Of-Pocket or catastrophic healthcare expenditures. This is evidenced by a similar finding from Malawi in which suffering from a chronic illness has a significant positive association with Out-Of-Pocket / catastrophic healthcare expenditures [68]. In the case of chronic illness, doubling household Out-Of-Pocket healthcare expenditure is consistent with another finding in a study from Bangladesh's population [69]. Moreover, in Ethiopia, the odds of facing catastrophic healthcare expenditures among hospitalized subjects was about eight times that of the non-hospitalized subjects [44]. Our finding that hospitalizations increased the incidence of catastrophic health expenditures is consistent with findings from other studies from developing countries, Malawi, in which having at least one household member hospitalized increased the odds of catastrophic health expenditures [70]. These effects are common in Low and Middle-Income Countries (LMICs) where many households rely on Out-Of-Pocket for payment of healthcare services. Such reliance places 
financial burden on households which may leads to catastrophic expenditure and poverty and leaves members of the households in a vicious circle of poverty and ill health. Therefore, the findings of this systematic review and meta-analysis, advance the need to understand the extent of burden of household Out-Of-Pocket healthcare expenditures and its associated risk factors in Low and Middle-Income Countries (LMICs), including Ethiopia, to design and strengthen strategies for financial protection at national level.

\section{Strength and limitations of the study}

To the best of our knowledge, this meta-analysis seems to be the first of its kind in Ethiopia to estimate the pooled estimates of the burden of household Out-Of-Pocket healthcare expenditures in Ethiopia. We also identified the influencing factors of Out-of-Pocket healthcare expenditures / catastrophic healthcare expenditure. However, our study has the following potential limitations both at the study and review level, which may affect the overall conclusions reached. First, for example, at a study level, the included economic studies varied in methodological rigour and quality of reporting, and amount of evidence cited to support claims. The study designs of the studies investigating the burden of household Out-Of-Pocket healthcare expenditures have to be evaluated against the standards expected in current practice. The reliability of different methods of evaluation of household Out-Of-Pocket healthcare expenditures will also have to be considered. Second, despite the drawbacks of our inclusion criteria, a benefit is that our results provide a clearer and more relevant assessment of the economic impact of the burden of household Out-OfPocket healthcare expenditures in Ethiopia. At a review level also, as discussed within the practical issues, study heterogeneity in definitions of household Out-Of-Pocket healthcare expenditures outcomes may affect the quality of pooled data. The issue of forgoing treatments was also not captured in the review process.

\section{Conclusions}

This systematic review and meta-analysis revealedthe evidence of inequity in financial hardship that the burden of household Out-Of-Pocket / catastrophic healthcare expenditures gap persists between the richest and the poorest Ethiopian households that is unfair and unjust. Our study also highlights relevant policy variables such as socioeconomic, education, and presence of illness gradient in the burden of household Out-Of-Pocket / catastrophic healthcare expenditures in Ethiopia. Nearly two out of four households experienced catastrophic healthcare expenditure in Ethiopia. The poorest households were more affected by Out-Of-Pocket / catastrophic healthcare expenditures. Being poor, not having a formal education, and having chronic illness were found to be predictors of the burden of household Out-OfPocket healthcare expenditures in Ethiopia. The negative impact of chronic illness in terms of increased household health expenditure has been demonstrated. Households resorted to various coping strategies to meet the burden of household Out-Of-Pocket / catastrophic healthcare expenditures on seeking healthcare during illness. Hence, reduction of financing hardship requires reduction of the burden of household Out-Of-Pocket / catastrophic healthcare expenditures.

Therefore, to reduce the detected disparities in seeking healthcare among Ethiopian households, national healthcare priorities should target poor households. This calls for the Ministry of Health to improve the challenges and their impact on equity and design better prepayment policies and strengthen financial protection strategies to protect more vulnerable Ethiopian households.. Furthermore, as inequity in the financial hardship in healthcareseeking is a major concern in Ethiopia, households facing high Out-Of-Pocket / catastrophic healthcare expenditures might forgo receiving healthcare because of unaffordable charges. Therefore, this issue requires further investigation on-going debates and research in improving the Ethiopian healthcare system.

Finally, based on our study, we suggest examining the feasibility of Community-Based Health Insurance (CNHI) initiatives that pools members' premium payments into a collective fund. This is because while the government is trying to expand financial protection mechanism, a large segment of the population is still suffering from financial hardship during seeking healthcare, especially the rural poorest households, Besides improving an individual's education may also be a long-term strategy and can also contribute to a more equitable burden of household Out-Of-Pocket healthcare expenditure and further equitable health.

\section{Policy implications}

This review highlights a base for key policy implications as the burden of household Out-Of-Pocket healthcare expenditure is an indicator of the effectiveness of the current healthcare financing schemes in Ethiopia. Although the burden of household Out-OfPocket healthcare expenditure varies depending on the approach and study design, the problem of household Out-Of-Pocket / catastrophic healthcare expenditure in Ethiopia cannot be denied. Therefore, the government of Ethiopia needs to strengthen the current community-based health insurance for rural households and social health insurance for the formal sector. Vulnerable groups, such as low educational status, low-income 
households, and households with chronic / any illness, should be a priority in the improvement of access to essential healthcare.

\author{
Abbreviations \\ OOP: Out-Of-Pocket healthcare expenditure; CHE: Catastrophic healthcare \\ expenditures; JBI: Joanna Briggs Institute standardized critical appraisal tools; \\ NOS: The Newcastle-Ottawa Scale quality assessment scale; LMICs: Low and \\ Middle-Income Countries.
}

\section{Supplementary Information}

The online version contains supplementary material available at https://doi. org/10.1186/s12939-021-01610-3.

Additional file 1. Completed PRISMA 2020 checklist. The checklist was used to highlight the important components addressed while preparing this manuscript of systematic review and meta-analysis.

Additional file 2. Data extraction summary table or abstraction format. The table was used to present the ways of data collection (study characteristics and outcome measures) in Microsoft excel format. It also contains raw data for outcome analyses.

Additional file 3. The Joanna Briggs Institute's (JBI) standardized critical appraisal tools or checklist used to assess the trustworthiness, relevance, and results of published papers_2017.

Additional file 4. A modified version of 'The Newcastle-Ottawa Scale (NOS)' quality assessment scale.

\section{Acknowledgements}

The authors would like to acknowledge the authors of primary studies. We would also like to acknowledge Dilla University for financial support.

\section{Documenting amendments}

Was recorded to distinguish from the original submission.

\section{Authors' contributions}

MTB conceived the idea and designed the study, will participate in data extraction, data curation, drafting and reviewing the protocol, formal analysis, manuscript preparation, and supervision. RHK, MFS, and SMA will contribute to data extraction, validation, writing, drafting, and editing of the manuscript. All the authors read and approved the final version of the protocol to be considered for publication.

\section{Funding}

Dilla University provided a fund to support this review.

\section{Availability of data and materials}

All relevant data are available within the paper and as supplementary files.

\section{Declarations}

Ethics approval and consent to participate

Not applicable.

\section{Consent for publication}

Not applicable.

\section{Competing interests}

The authors declare that they have no competing interests.

\section{Author details}

${ }^{1}$ School of Public Health, College of Health Sciences and Medicine, Dilla University, Dilla, Ethiopia. ${ }^{2}$ Hawassa, Ethiopia. ${ }^{3}$ Department of Nutrition, College of Health Sciences and Medicine, Dilla University, Dilla, Ethiopia. ${ }^{4}$ Department of Reproductive Health, College of Health Sciences and Medicine, Dilla
University, Dilla, Ethiopia. ${ }^{5}$ Department of Anaesthesiology, College of Health Sciences and Medicine, Dilla University, Dilla, Ethiopia.

Received: 27 October 2021 Accepted: 29 November 2021

Published online: 31 January 2022

\section{References}

1. Doshmangir L, Yousefi M, Hasanpoor E, Eshtiagh B, Haghparast-Bidgoli $H$. Determinants of catastrophic health expenditures in Iran: a systematic review and meta-analysis. Cost Eff Res Alloc. 2020;18(1):17.

2. Jakovljevic MB. BRIC's growing share of Global Health spending and their diverging pathways. Front Public Health. 2015;3:135.

3. O'Donnell O, Doorslaer E, Wagstaff A, Lindelow M. Analyzing health equity using household survey data: a guide to techniques and their implementation World Bank publications, the World Bank, number 6896; 2008

4. Xu K, Evans DB, Carrin G, Aguilar-Rivera AM, Musgrove P, Evans T. Protecting households from catastrophic health spending. Health Affairs (Project Hope). 2007;26(4):972-83.

5. World Health Organization. The World health report: health systems: improving performance. Geneva: World Health Organization; 2000.

6. Aregbeshola BS, Khan SM. Out-of-pocket payments, catastrophic health expenditure and poverty among households in Nigeria 2010. Int J Health Policy Manag. 2018;7(9):798-806.

7. Xu K, Saksena P, Evans DB. Health financing and access to effective interventions. World Heal Organ. 2010; background paper: 8.

8. World Health Organization, Global Spending on Health: A World in Transition. Geneva; 2019. (WHO/HIS/HGF/HFWorkingPaper/19.4). Licence: CC BY-NC-SA 3.0 IGO

9. Alam K, Mahal A. Economic impacts of health shocks on households in low and middle-income countries: a review of the literature. Glob Health. 2014;10:21

10. Ethiopia Federal Ministry of Health. Ethiopia's Fifth National Health Accounts 2010/2011. Addis Ababa: The Ethiopian Federal Ministry of Health; 2014

11. Ethiopia Federal Ministry of Health. Ethiopia's Seventh National Health Accounts 2016/2017. Addis Ababa: The Ethiopian Federal Ministry of Health; 2019.

12. Kivunja C. Distinguishing between theory, theoretical framework, and conceptual framework: a systematic review of lessons from the field. Int J Higher Educ. 2018;7:44.

13. Kiros M, Dessie E, Jbaily A, Tolla MT, Johansson KA, Norheim OF, et al. The burden of household out-of-pocket health expenditures in Ethiopia: estimates from a nationally representative survey (2015-16). Health Policy Plan. 2020;35(8):1003-10.

14. Borde MT, Loha E, Johansson KA, Lindtjørn B. Financial risk of seeking maternal and neonatal healthcare in southern Ethiopia: a cohort study of rural households. Int J Equity Health. 2020;19(1):69.

15. OECD. "Burden of out-of-pocket health expenditure", in Health at a Glance 2009: OECD Indicators. Paris: OECD Publishing; 2009. https://doi.org/10. 1787/health_glance-2009-62-en; Accessed on 27 Nov 2021

16. Page MJ, McKenzie JE, Bossuyt PM, Boutron I, Hoffmann TC, Mulrow CD, et al. The PRISMA 2020 statement: an updated guideline for reporting systematic reviews. Syst Rev. 2021;10(1):89.

17. Moges Tadesse, Robel Hussen, Mohammed Feyisso, Semagn Mekonnen. The burden of household out-of-pocket healthcare expenditures in Ethiopia: a systematic review and meta-analysis. PROSPERO 2021 CRD42021255977 Available from: https://www.crd.york.ac.uk/prospero/ display_record.php?ID=CRD42021255977.

18. Liberati A, Altman DG, Tetzlaff J, Mulrow C, Gøtzsche PC, et al. The PRISMA Statement for Reporting Systematic Reviews and Meta-Analyses of Studies That Evaluate Health Care Interventions: Explanation and Elaboration. PLoS Med. 2009;6(7):e1000100. https://doi.org/10.1371/journal.pmed. 1000100.

19. Marušić MF, Fidahić M, Cepeha CM, Farcaș LG, Tseke A, Puljak L. Methodological tools and sensitivity analysis for assessing quality or risk of bias used in systematic reviews published in the high-impact anesthesiology journals. BMC Med Res Methodol. 2020;20(1):121. 
20. Harrer M, Cuijpers P, Furukawa TA, Ebert DD. Doing Meta-analysis with R: a hands-on guide. 1st ed. Boca Raton: Chapman \& Hall/CRC Press.

21. OECD. Health at a Glance 2011: OECD Indicators: OECD Publishing; 2011, Accessed on 18 May 2021. https://doi.org/10.1787/health_ glance-2011-en.

22. Xu K, Evans DB, Kawabata K, Zeramdini R, Klavus J, Murray CJ. Household catastrophic health expenditure: a multicountry analysis. Lancet. 2003;362(9378):111-7.

23. Joanna Briggs Institute: Critical appraisal tools: JBI's standardized critical appraisal tools to assist in assessing the trustworthiness, relevance and results of published papers, Available at https://jbi.global/critical-appra isal-tools. Accessed on 16 May 2021

24. Stang A. Critical evaluation of the Newcastle-Ottawa scale for the assessment of the quality of nonrandomized studies in meta-analyses. Eur J Epidemiol. 2010;25(9):603-5.

25. Moola S, Munn Z, Tufanaru C, Aromataris E, Sears K, Sfetcu R, et al. Chapter 7: Systematic reviews of aetiology and risk. In: Aromataris E, Munn Z, editors. JBI Manual for Evidence Synthesis. JBI; 2020. Available from https://synthesismanual.jbi.global.

26. Moola S, Munn Z, Tufanaru C, Aromataris E, Sears K, Sfetcu R, et al. Chapter 6: Systematic reviews of economic evidence. In: Aromataris E, Munn Z, editors. JBI Manual for Evidence Synthesis. JBI; 2020. Available from https://synthesismanual.jbi.global.

27. Review Manager (RevMan) [Computer program]. Version 5.4.1. The Cochrane Collaboration, 2020

28. Borenstein M, Hedges LV, Higgins JP, Rothstein HR. A basic introduction to fixed-effect and random-effects models for meta-analysis. Res Synth Methods. 2010;1 (2):97-111.

29. Higgins JP, Thompson SG, Deeks JJ, Altman DG. Measuring inconsistency in meta-analyses. BMJ. 2003;327(7414):557-60.

30. Ahmed I, Sutton AJ, Riley D. Assessment of publication bias, selection bias, and unavailable data in meta-analyses using individual participant data: a database survey. BMJ. 2012;344:1-10.

31. Borenstein $M$, Hedges L, Rothstein H. Meta-Analysis: fixed effect vs. random effects; 2007. p. 162.

32. Cochrane handbook for systematic reviews of intervention version 5.1.0 (updated march 2011): The Cochrane collaboration; 2011.

33. Tibebe A, Amarech G, Melesse T, Mariam DH. Examining out of pocket payments for maternal health in rural Ethiopia: paradox of free health care un-affordability. Ethiop J Health Dev. 2012;26:251-7.

34. Asres A, Jerene D, Deressa W. Pre- and post-diagnosis costs of tuberculosis to patients on Directly Observed Treatment Short course in districts of southwestern Ethiopia: a longitudinal study. J Health Popul Nutr. 2018:37(1):15.

35. Hailemichael Y, Hailemariam D, Tirfessa K, Docrat S, Alem A, Medhin G, et al. Catastrophic out-of-pocket payments for households of people with severe mental disorder: a comparative study in rural Ethiopia. Int J Ment Heal Syst. 2019;13(1):39.

36. Hailemichael Y, Hanlon C, Tirfessa K, Docrat S, Alem A, Medhin G, et al. Catastrophic health expenditure and impoverishment in households of persons with depression: a cross-sectional, comparative study in rural Ethiopia. BMC Public Health. 2019;19(1):930.

37. Getachew B, Liabsuetrakul T. Health care expenditure for delivery care between maternity waiting home users and nonusers in Ethiopia. Int J Health Plann Manag. 2019;34(2):e1334-45.

38. Geremew M, Gedefaw M, Tsegay G, Kassa GM. Magnitude of Out of Pocket Health Expenditures and Associated Factors among Civil Servants. Int J Public Health Sci. 2015:4(4):332-7.

39. Mekonen AM, Gebregziabher MG, Teferra AS. The effect of communitybased health insurance on catastrophic health expenditure in Northeast Ethiopia: a cross-sectional study. PLoS One. 2018;13(10):e0205972.

40. Teni FS, Gebresillassie BM, Birru EM, Belachew SA, Tefera YG, Wubishet BL, et al. Costs incurred by outpatients at a university hospital in northwestern Ethiopia: a cross-sectional study. BMC Health Serv Res. 2018:18(1):842.

41. Tsega G, Getaneh G, Taddesse G. Are Ethiopian diabetic patients protected from financial hardship? PLoS One. 2021;16(1):e0245839.

42. Shumet Y, Mohammed SA, Kahissay MH, Demeke B. Catastrophic health expenditure among chronic patients attending Dessie referral hospital, Northeast Ethiopia. Clinicoecon Outcomes Res. 2021;13:99-107. https:/ doi.org/10.2147/CEOR.S291463.
43. Getahun B, Wubie M, Dejenu G, Manyazewal T. Tuberculosis care strategies and their economic consequences for patients: the missing link to end tuberculosis. Infect Dis Poverty. 2016;5(1):93.

44. Tolla MT, Norheim OF, Verguet S, Bekele A, Amenu K, Abdisa SG, et al. Outof-pocket expenditures for prevention and treatment of cardiovascular disease in general and specialised cardiac hospitals in Addis Ababa, Ethiopia: a cross-sectional cohort study. BMJ Glob Health. 2017;2(2):e000280.

45. Bedane SN. Out of Pocket Expenditures among Hypertensive Patients and their Households who Visit Public Hospitals in Addis Ababa, Ethiopia. Health Econ Outcome Res Open Access. 2018;4:147. https://doi.org/10. 4172/2471-268x/1000147.

46. Alemu A, Aklilu M, Tadele W. Magnitude and Factors Affecting Out-ofPocket Medical Expenditure among Outpatients in ST.Paul Hospital Millennium College; Addis Ababa, Ethiopia. Int J Health Econ Policy. 2019;4(1):29-34. https://doi.org/10.11648/j.hep.20190401.14.

47. Kasahun GG, Gebretekle GB, Hailemichael Y, Woldemariam AA, Fenta TG. Catastrophic healthcare expenditure and coping strategies among patients attending cancer treatment services in Addis Ababa, Ethiopia. BMC Public Health. 2020;20(1):984.

48. Bogale T, Mariam DH, Ali A. Costs of illness and coping strategies in a coffee-growing rural district of Ethiopia. J Health Popul Nutr. 2005;23(2):192-9.

49. Deressa W, Hailemariam D, Ali A. Economic costs of epidemic malaria to households in rural Ethiopia. Trop Med Int Health. 2007;12(10):1148-56.

50. Zawudie AB, Lemma TD, Daka DW. Cost of hypertension illness and associated factors among patients attending hospitals in southwest Shewa zone, Oromia regional state, Ethiopia. Clinicoecon Outcomes Res. 2020;12:201-11.

51. Shikuro D, Yitayal M, Kebede A, Debie A. Catastrophic out-of-pocket health expenditure among rural households in the semi-pastoral community, Western Ethiopia: a community-based cross-sectional study. Clinicoecon Outcomes Res. 2020;12:761-9.

52. Assebe LF, Negussie EK, Jbaily A, Tolla MTT, Johansson KA. Financial burden of HIV and TB among patients in Ethiopia: a cross-sectional survey. BMJ Open. 2020;10(6):e036892.

53. Pearson L, Gandhi M, Admasu K, Keyes EB. User fees and maternity services in Ethiopia. Int J Gynaecol Obstet. 2011;115(3):310-5.

54. Miljeteig I, Defaye FB, Wakim P, Desalegn DN, Berhane Y, Norheim OF, et al. Financial risk protection at the bedside: how Ethiopian physicians try to minimize out-of-pocket health expenditures. PLoS One. 2019;14(2):e0212129.

55. Memirie ST, Metaferia ZS, Norheim OF, Levin CE, Verguet S, Johansson KA. Household expenditures on pneumonia and diarrhoea treatment in Ethiopia: a facility-based study. BMJ Glob Health. 2017;2(1):e000166.

56. World Bank, Ethiopia. A Country Status Report on Health and Poverty, Volume 2, Main Report. Washington, DC: @ World Bank; 2005. https://openk nowledge.worldbank.org/handle/10986/8687 License: CC BY 3.0 IG

57. Obse AG, Ataguba JE. Assessing medical impoverishment and associated factors in health care in Ethiopia. BMC Int Health Hum Rights. 2020;20(1):7.

58. Sedgwick P. Meta-analyses: how to read a funnel plot. BMJ. 2013;346:11342.

59. Sterne JAC, Sutton AJ, loannidis JPA, Terrin N, Jones DR, Lau J, et al. Recommendations for examining and interpreting funnel plot asymmetry in meta-analyses of randomised controlled trials. BMJ. 2011;343:d4002.

60. Saksena P, Antunes AF, Xu K, Musango L, Carrin G. Mutual health insurance in Rwanda: Evidence on access to care and financial risk protection. Health Policy. 2011;99(3):203-9.

61. Brinda EM, Andrés AR, Enemark U. Correlates of out-of-pocket and catastrophic health expenditures in Tanzania: results from a national household survey. BMC Int Health Hum Rights. 2014;14:5.

62. Buigut $\mathrm{S}$, Ettarh R, Amendah DD. Catastrophic health expenditure and its determinants in Kenya slum communities. Int J Equity Health. 2015;14(1):46

63. Myint C-Y, Pavlova M, Groot W. Catastrophic health care expenditure in Myanmar: policy implications in leading progress towards universal health coverage. Int J Equity Health. 2019;18(1):118.

64. Nguyen L, Lee JT, Hulse ESG, Hoang MV, Kim GB, Le DB. Health service utilization and out-of-pocket expenditure associated with the continuum of disability in Vietnam. Int J Environ Res Public Health. 2021;18(11):5657. 
65. Fan L, Hou X-Y, Liu Y, Chen S, Wang Q, Du W. Catastrophic Health Expenditure Associated With Frailty in Community-Dwelling Chinese Older Adults: A Prospective Cohort Analysis. Front Public Health. 2021;9:1299.

66. Li Y, Wu Q, Xu L, Legge D, Hao Y, Gao L, et al. Factors affecting catastrophic health expenditure and impoverishment from medical expenses in China: policy implications of universal health insurance. Bull World Health Organ. 2012;90(9):664-71.

67. Puteh SEW, Almualm Y. Catastrophic Health Expenditure among Developing Countries. Health Syst Policy Res. 2017;4:1. https://doi.org/10.21767/ 2254-9137.100069.

68. Nakovics MI, Brenner S, Bongololo G, Chinkhumba J, Kalmus O, Leppert G, et al. Determinants of healthcare-seeking and out-of-pocket expenditures in a "free" healthcare system: evidence from rural Malawi. Heal Econ Rev. 2020;10(1):14.

69. Molla AA, Chi C, Mondaca ALN. Predictors of high out-of-pocket healthcare expenditure: an analysis using Bangladesh household income and expenditure survey, 2010. BMC Health Serv Res. 2017;17(1):94.

70. Mulaga AN, Kamndaya MS, Masangwi SJ. Examining the incidence of catastrophic health expenditures and its determinants using multilevel logistic regression in Malawi. PLoS One. 2021;16(3):e0248752.

71. Moher D, Liberati A, Tetzlaff J, Altman DG, The PG. Preferred reporting items for systematic reviews and Meta-analyses: the PRISMA statement. PLoS Med. 2009;6(7):e1000097.

\section{Publisher's Note}

Springer Nature remains neutral with regard to jurisdictional claims in published maps and institutional affiliations.

- fast, convenient online submission

- thorough peer review by experienced researchers in your field

- rapid publication on acceptance

- support for research data, including large and complex data types

- gold Open Access which fosters wider collaboration and increased citations

- maximum visibility for your research: over $100 \mathrm{M}$ website views per year

At BMC, research is always in progress.

Learn more biomedcentral.com/submissions 